\title{
Research Paper \\ Study of the effectiveness of mindful sensorimotor interventions in the treatment of abnormal personality patterns leading to depression and anxiety: a mixed-method study
}

\section{Hamed Kashanaki ${ }^{1}$, Seyed Saeid Pournaghash Tehrani ${ }^{2}$, Nima Ghorbani ${ }^{3}$, Hadi Bahrami Ehsan ${ }^{3}$}

1. Ph.D Student, Faculty of Psychology, University of Tehran, Tehran, Iran.

2. Associate Professor, Department of Psychology, University of Tehran, Tehran, Iran.

3. Professor, Department of Psychology, University of Tehran, Tehran, Iran.

Citation: Kashanaki H, Pournaghash Tehrani S.S, Ghorbani N, Bahrami Ehsan H. Study of the effectiveness of mindful sensorimotor interventions in the treatment of abnormal personality patterns leading to depression and anxiety: a mixed-method study. J of Psychological Science. 2021; 20(106): 1699-1716.

URL: https://psychologicalscience.ir/article-1-1290-fa.html
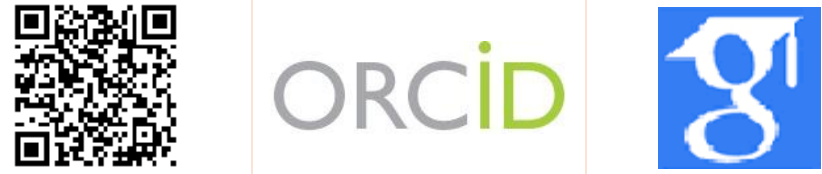

\section{$\underline{10.52547 / J P S .20 .106 .1699}$}

A R T I C L E I N F O A B S T R A C T

Keywords:

SensoriMotor,

Mindful,

Personality,

Health

Received: 05 Jun 2021

Accepted: 01 Jul 2021

Available: 22 Dec 2021 personality?
Background: Methods of achieving mindfulness have been implemented by slowing down movement, creating stillness, and following the traditional teachings of Buddhism. The long-term effectiveness of traditional mindfulness methods on anxiety and depression has been associated with conflicting results. Recently, bodily, dynamic, and objective interventions while moving and playing on the unconscious and strengthening consciousness for the integration of mind and body have been suggested. Can these therapeutic exercises change the abnormal patterns of an anxious and depressed

Aims: This study aimed to study the effectiveness of mindful sensorimotor interventions in treating abnormal personality patterns leading to anxiety and depression in clients seeking psychotherapy.

Methods: This research is an explanatory mixed-method study. The first study was a quasiexperimental study with pre-test and post-test. The statistical population of the study was the clients of psychology clinics in Tehran. a sample of 20 ( 7 women and 13 men) of the clients of a psychology clinic in Tehran responded to Castello-Comrey (1967) anxiety and depression questionnaires before and after eight weeks of mindful sensorimotor interventions (Kashanaki et al., 2021). In the second study, during and after mindful sensorimotor interventions, personality disorders, mental health, and personality traits predicting anxiety and depression in one client were assessed by the SWAP personality test (Shedler and Westen, 2007).

Results: The results of a correlated t-test showed that mindful sensorimotor interventions are effective in reducing anxiety $(\mathrm{p}<0.00001)$ and depression $(\mathrm{p}<0.05)$. The second study showed that the patient changes his pathological personality patterns and personality disorder by interventions; this intervention transformed immature defenses into more mature defenses and increased mental health factors in him, which led to a decrease in anxiety and depression.

Conclusion: The results of this study showed the effectiveness of mindful sensorimotor interventions in reducing anxiety and depression. These challenging interventions and a variety of games are likely to empower and increase the capacity of the mind and body and motivate them to endure anxiety and cope with depression.

* Corresponding Author: Seyed Saeid Pournaghash Tehrani, Associate Professor, Department of Psychology, University of Tehran, Tehran, Iran.

E-mail: Spnaghash@ut.ac.ir

Tel: (+98) 9122074388

2476-5740/ (C) 2021 The Authors. This is an open access article under the CC BY-NC-ND license

(https://creativecommons.org/licenses/by-nc/4.0/). 


\section{Extended Abstract}

\section{Introduction}

Due to the high correlation between clinical disorders such as anxiety and depression and personality disorder, an integrated model of psychopathology that examines the common and distinctive etiological mechanism is necessary to treat depression and anxiety. Numerous studies have examined personality traits leading to anxiety and depression (Hong et al., 2021; Grouchi et al., 2020; Zhang, Dong, and Zhao, 2020). Most of these studies emphasized the role of emotion regulation problems as a common feature of anxious and depressed personality traits. Many researchers and therapists have recently considered mindfulness as one of the essential processes of emotion regulation.

Mindfulness improves people's physical and mental problems by creating a distance between action and intention, creating the capacity to observe the senses, thoughts, and feelings, and regulating the physical and mental flow of tensions. So far, mindfulness methods, such as stress reduction terms based on consciousness and similar therapies, have been implemented by slowing down movement, creating stillness, stopping, and following the same traditional teachings of Buddhism (Kabat Zain, 2019). The generality of the protocol of terms and not its design following the mental and physical capacity of each person, the lack of meaning to the emotions and sensations, and the lack of similarity of the training place (stillness, silence, and tranquility) to the noisy world full of movement and movement of the natural world including There are criticisms of this traditional view and meditation methods to achieve mindfulness. In other words, these methods are only a moderate and challenging way to achieve a healthy experience (Demarzo et al., 2015). When a person's strength increases, the person's mindfulness capacity increase (Mansouri and Besharat, 1398); As a result, objective interventions that work on the strength of mind and body and mindfulness at the same time can be more effective. For this reason, the first study of the present study examines the effectiveness of sensory-motor mindful interventions in reducing anxiety and depression by considering movement instead of stillness as a purposeful activity and using dynamic, objective, and meaningful interventions. After evaluating the effectiveness, if the research hypothesis is confirmed, the second study answers how these interventions will be effective and how they will change the personality traits that lead to depression and anxiety.

\section{Method}

This research was conducted by sequential mixed Explanatory method. In this method, first quantitative data were collected and analyzed, and then qualitative data were used to evaluate the effectiveness of the intervention process. In this method, qualitative findings are designed to compensate for the weakness of quantitative research results and explain the findings or a comprehensive study of why quantitative results occurred. The most common type is to place qualitative data in experimental or quasiexperimental design rather than interpret and strengthen its implementation (McKim, 2017). The qualitative study method of the research is an in-depth dynamic interview to assess personality, emotional regulation, mental health, and disorders predicting anxiety and depression. The interview duration is 510 hours, and it is performed in the form of conscious and unconscious assessment of the clients' biological, psychological, and communication symptoms. The first study of this research is quasi-experimental in terms of data collection and data and applied research in terms of purpose. Behavioral sensory-motor therapeutic interSpecialist therapists performed behavioral sensory-motor therapeutic interventions week). The statistical population of this study in the second study includes all adults who could answer the research questions and were ready to cooperate in advancing the research objectives. The research was conducted in Tehran. The patient population was referred to a counseling clinic in Tehran. The study sample consisted of 20 people who were referred to the clinic due to symptoms of anxiety or depression and were subject to receiving at least one official diagnosis of one of the problems. The number of participants in the present study was selected based on articles reviewed in health that emphasized the importance of a qualitative method of performing interventions and did not differentiate between the 


\section{Monthly Journal of Psychological Science}

Vol. 20, No. 106, Winter(January) 2021

number of samples (Goldberg et al., 2017). The total number of participants included 20 people with a mean age of 31.76 and a standard deviation of 8.5 from 18 to 52 years. Regarding gender, 14 men (70\%) and six women $(30 \%)$ participated in the present study. Inclusion criteria include A) Anxiety or depression and related disorders (diagnosis by a clinical evaluator), B) Ability to understand and respond to self-report tools. C) Satisfaction with patient participation and exclusion and exclusion criteria included illiteracy or inability to respond to self-report tools. In order to statistically analyze the research data, descriptive statistical methods and indicators including frequency, mean, standard deviation, and inferential statistics tests have been used. All steps have been performed using SPSS statistical software. Sensory-motor mindfulness interventions were performed on the research sample for eight weeks in 90-minute sessions (one session per week). To determine the effect of the term at the beginning and end of the term, the dependent variable was measured by participants' response to Castello and Camry's (1967) Anxiety and Depression Questionnaire and compared by paired t-test, pre-test, and post-test in the group. To explain the effectiveness of the intervention, the second study of this study was conducted using a clinical case study method based on the bio-psychosocial model of health and a personality model. Patient personality and normal personality patterns during and after the interventions were evaluated using Schedler and Westen (Swap) evaluation test.

Table 1. Sample of interventions

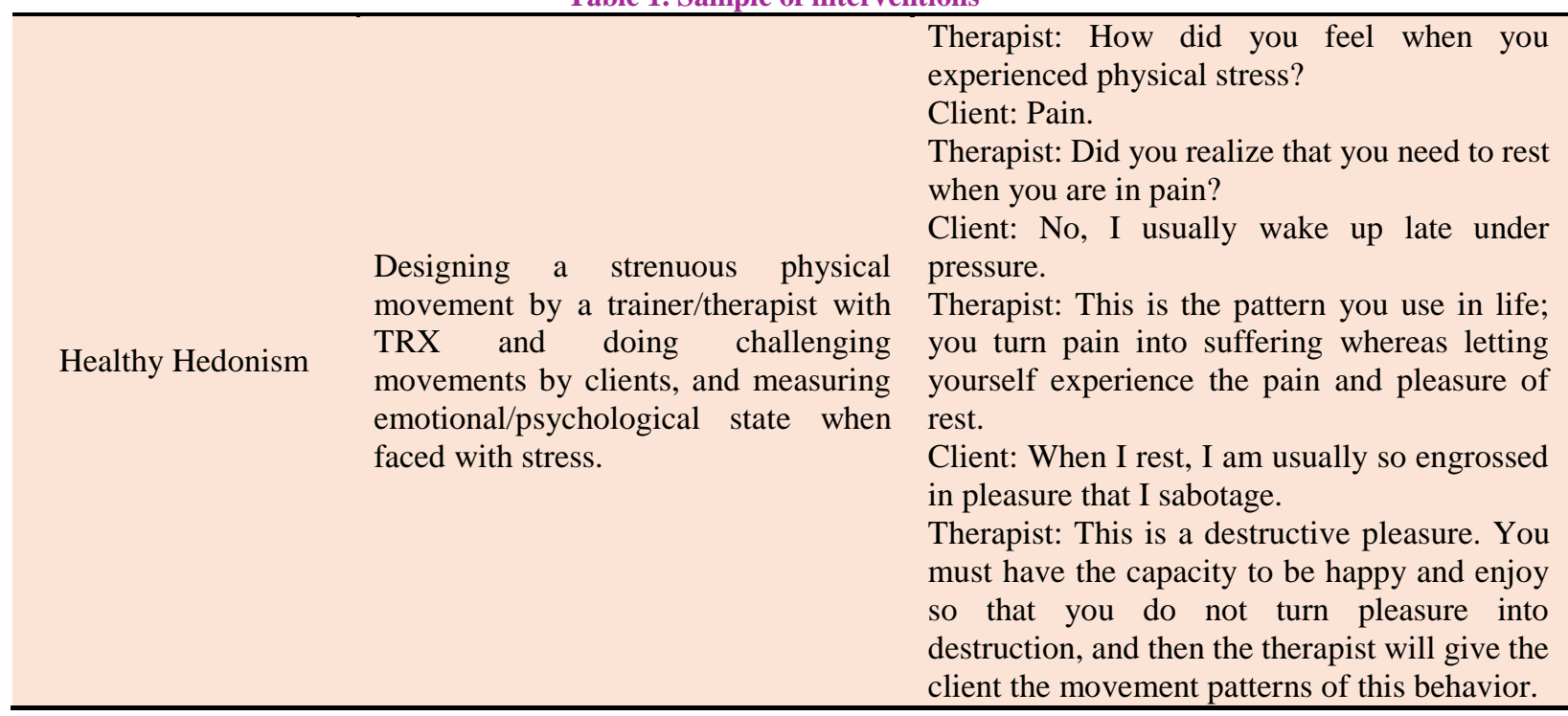

\section{Results}

This study showed a significant correlation between pre-test and post-test $(\mathrm{p}<0.01)$, which provides the conditions for performing paired t-test.

Based on the results of this table, it was found that the difference between the mean of pre-test and post-test is significant for 20 participants $(\mathrm{p}<010)$. Therefore, it can be said that interventions reduce anxiety. Based on the results of this table, it was found that the difference between the mean of pre-test and post-test is significant for 20 participants ( $\mathrm{p}<50$ ). Therefore, it can be said that mindful sensory-motor interventions reduce depression.
In the second study, a patient swap test was performed during and after the interventions, and the results are listed below.

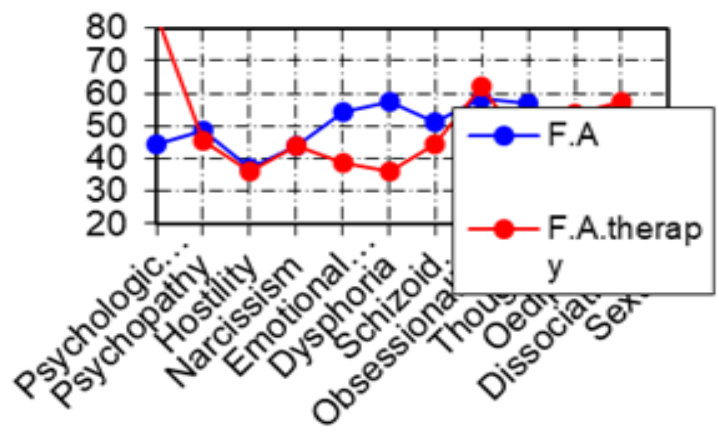




\section{Monthly Journal of Psychological Science}

According to the Figure, an increase in the objective mental health index occurred after treatment. These characteristics in the test include mental strength, self-awareness, the meaning of life experiences, and the capacity for lovemaking. Also, dysfunction of emotion regulation, thought disorder, and schizoid orientation are reduced. In general, all patients' distorted personality patterns have decreased after treatment, and mental health has improved.

\section{Conclusion}

The trainer or therapist activates the right hemisphere using motor-sensory consciousness interventions; Controlled activation of the right hemisphere of the brain awakens repressed emotions, and then their coach or therapist interprets them; This style of meaning determines the coherence of the two hemispheres of the brain. According to recent research, the method that can awaken and make sense of right hemisphere emotions in a controlled way is known as the most up-to-date and practical emotionoriented therapeutic intervention (Schore, 2020).

Mindful sensory-motor interventions reduced depression in clients by changing distorted personality patterns. Depression is treated when the emotions are restrained, and the individual's talents are suppressed (Ton et al., 2020). When the mind and body become cohesive, one can release inhibited energies. Here the rules of games and movements of these energies lead to construction, which is the key to the treatment and effectiveness of interventions on depression. Long-term research on psychotherapy,
Vol. 20, No. 106, Winter(January) 2021

especially cognitive psychotherapy, has often shown that both depression and anxiety will recur after treatment is over (Town et al., 2020); While the interventions of the present study, seeing the energy behind depression and anxiety, uses them for selfactualization and recovery, and this is the difference between repressive interventions and repressive interventions. Physical de-repression is the issue that will lead to treatment in long-term research in the field of anxiety and depression (Prince et al., 2020).

According to recent theories in mindfulness, any method that determines the cohesion of mind and body can be known as a mindfulness-based therapeutic approach. (Siegel, 2020). Therefore, it can be said that sensory-motor interventions are a mindfulness-based therapeutic approach that is associated with a significant reduction in anxiety and depression and determine mental health and cohesion of mind and body.

\section{Ethical Considerations}

Compliance with ethical guidelines: The authors extracted this article from the $\mathrm{PhD}$ dissertation of the first author, which approved under date, 03.02.2020 in the Faculty of Psychology, University of Tehran.

Funding: This study was conducted as a $\mathrm{PhD}$ thesis with no financial support.

Authors' contribution: The first author was the senior author, the second and the third were the supervisors and the forth was the advisors.

Conflict of interest: The authors declare no conflict of interest for this study.

Acknowledgments: I would like to appreciate the supervisor, the advisors, and the psychology clinic participants. 
بررسى اثربخشى مداخلات بهشيار حسى حر كتى در درمان الكوهاى كث كار شخصيت افسرده و مضطرب: يك مطالعه

\section{آميخته}

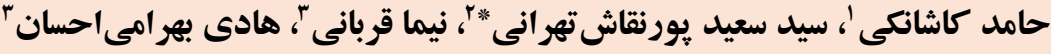

ا. كانديداى دكترى روانشناسى سلامت، دانشكاه تهران، تهران، ايران.

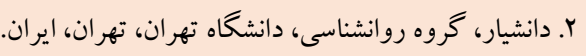

r. r. استاد، گروه روانشناسى دانشخاه تهران، تهران، ايران.

جكيu"

زمينه: تحقيقات نشان داده است روشهاى سنتى بهشيارى با دورههاى كاهش استرس بر بايه كند كردن حركت، ايجاد سكون و دنبال كردن آموزههاى سنتى بوديسم اجرا شدهاند، اما اثربخشى طولانىمدت اين روشها ها بر اضطر اب و افسردگى با نتايج ضد و نقيضى همراه بودهاست.

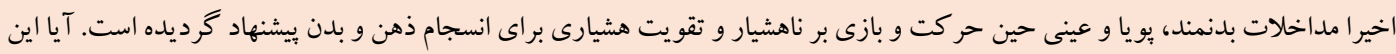

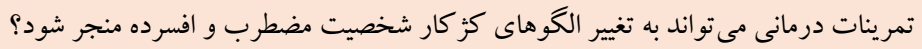

هدف: اين ثئوهش با هدف بررسى اثربخشى مداخلات بهشيار حسى حر كتى در درمان الكوهاى كز كار شخصيت منجر به اضطراب و

$$
\text { افسردگى مراجعين متقاضى روان درمانى اجرا شد. }
$$

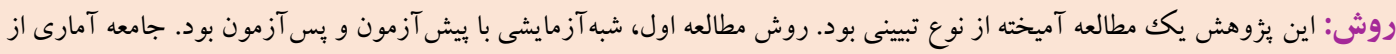

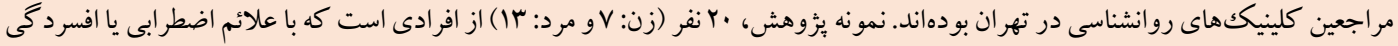

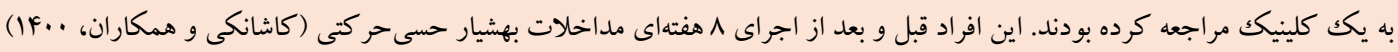

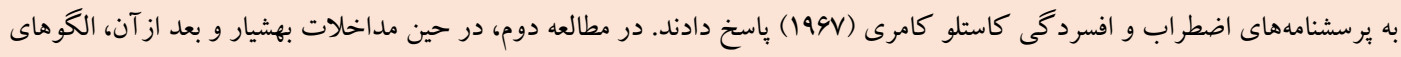
كز كار شخصيت، سلامتروان و خصيصه هاى شخصيتى بيشينى كننده اضطراب و افسردگى يكى از مراجعين، توسط آزمون شخصيت

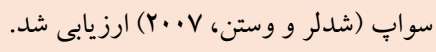

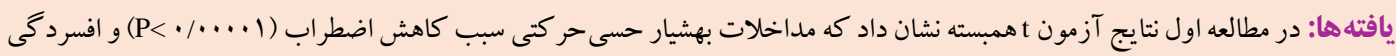
(P< مى شود و مطالعه دوم نشان دهنده تغيير الكوهاى كز كار شخصيت بيمار توسط مداخلات، تبديل دفاع هاى نايخته به دفاعهاى

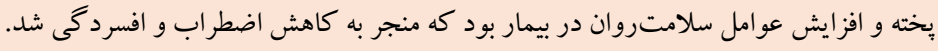

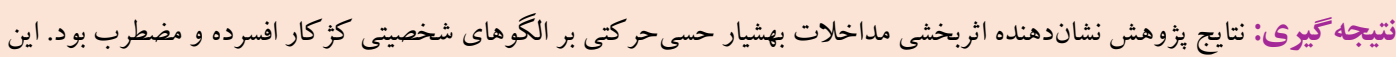

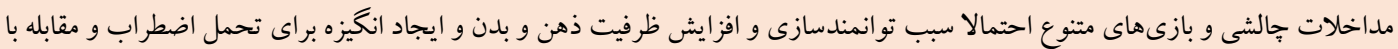

$$
\text { افسردگى مى شود. }
$$

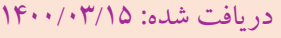

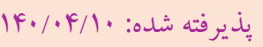

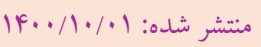

* نويسنده مسئول: سيد سعيد يورنقاش تهرانى، دانشيار، گروه روانشناسى، دانشگاه تهران، تهران، ايران.

رايانامه: Spnaghash@ut.ac.ir 
مراجع حين ارتباط با درمانگر بررسى مىشود. در رواندرمانى يويشى

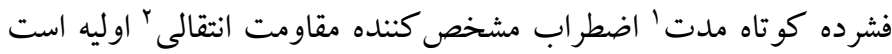
بدين معنى كه درمانكر با توجه به اضطراب، به ناهشيار بيمار نزديكك

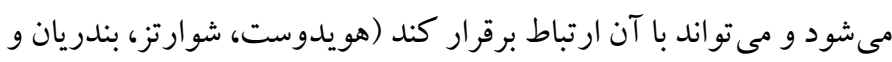

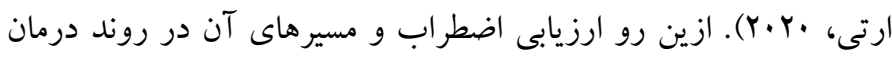

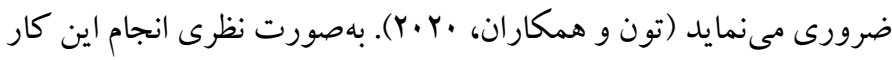

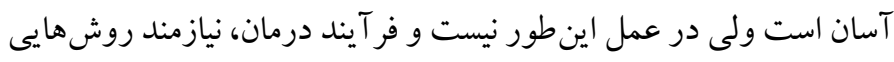

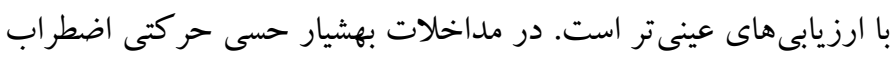

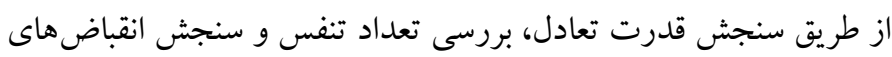

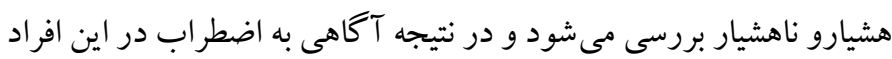

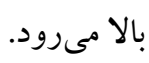
تنش عضلات مخطط كه دربر گيرنده تنش مزمن در بدن است، در ماهيجه

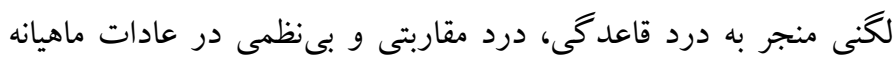
مى شو د. تنش ماهيجه همجنين مى تو اند منجر به ايجاد فشار در كلو و اشكال

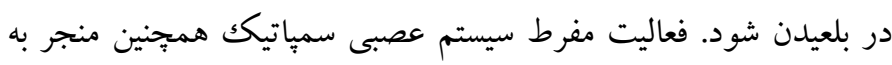

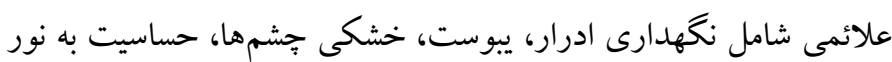
درنتيجه انبساط مردمك ها، غش كردن، از دست دادن هشيارى، گيجى و

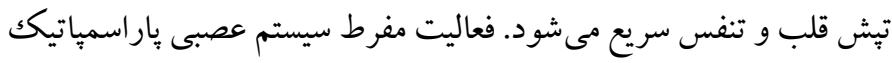

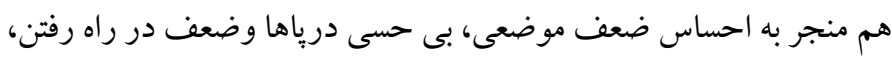

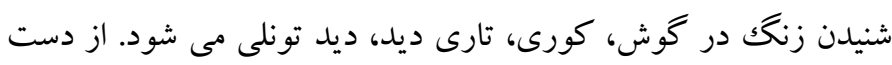

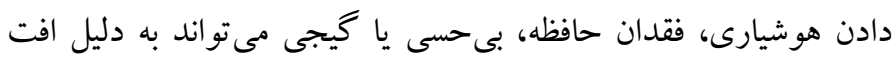

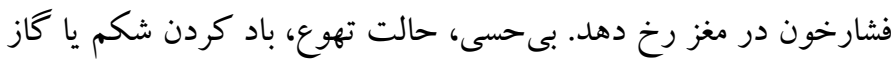

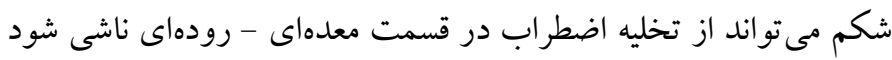

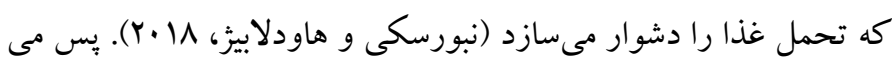

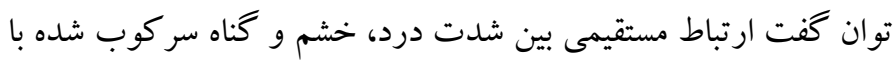
الكوى اضطرابى و مقاومت بيمارانى كه تحت رواندرمانى قرار گرفنتند، وجود دارد. فردى كه تجربه فراوانى از سركوب خشمب دمارئ دارد. به احتمال زياد

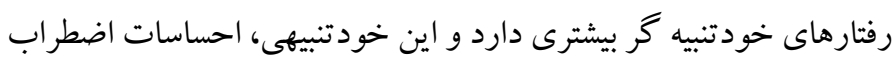

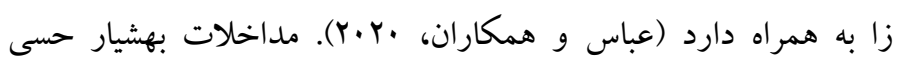

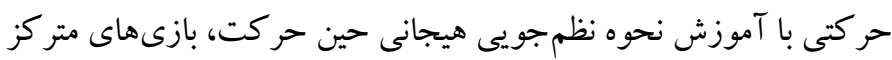

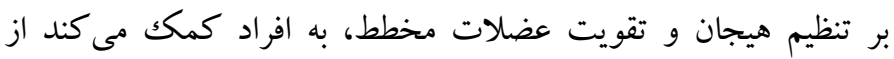

${ }^{2}$. Transference Resistance
مقلفمه

اضطراب و افسردگى از رايجترين بيمارىهاى عصر حاضر هستند كه همه

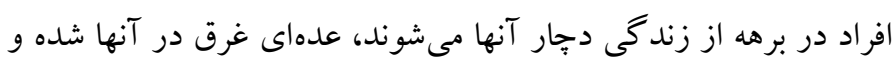

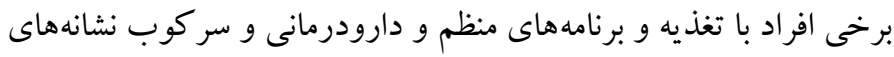

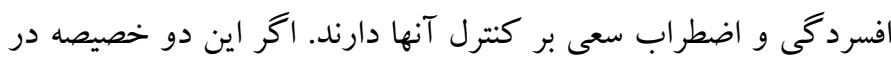

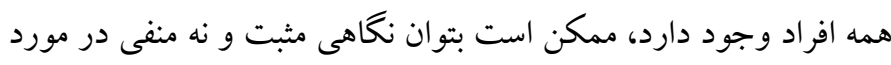
آنها داشت. اضطراب زمانى كه سالم تنظيم شود كليد مسيريابى مؤثر،

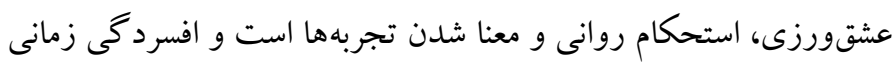

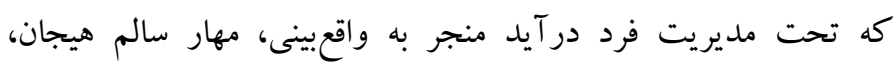

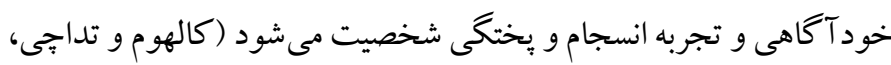

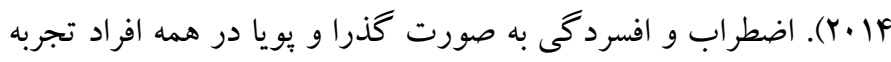
مىشوند و اين درك لحظهاى آنها و خود آكاه شدن به آنهاست كه سبب

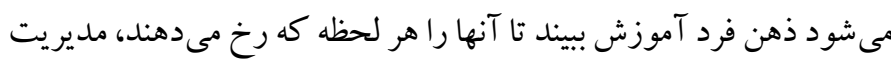

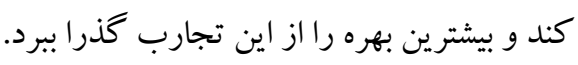

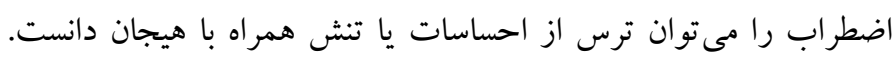

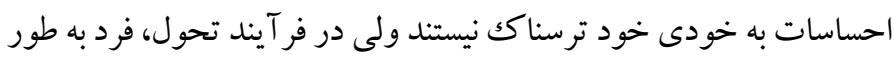

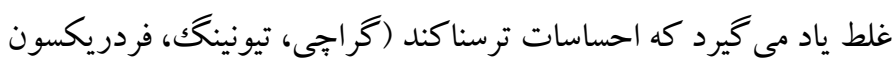

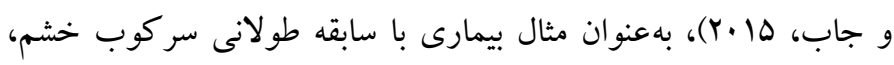

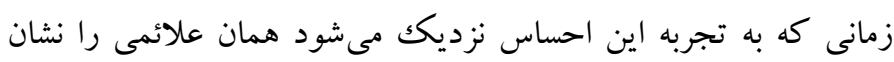
مى دهد كه بيمار مبتلا به ترس مرضى در مواجهه با منبع اضطراب (فرضاً

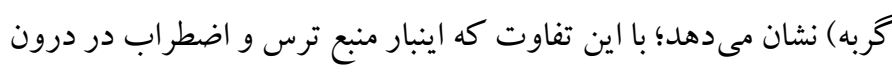

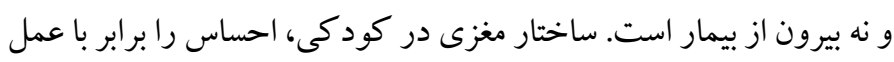

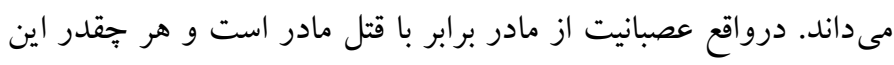

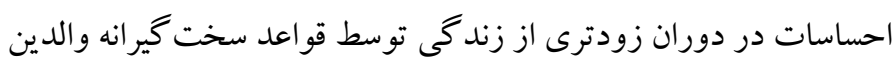

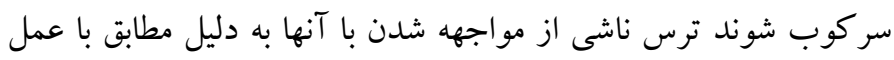

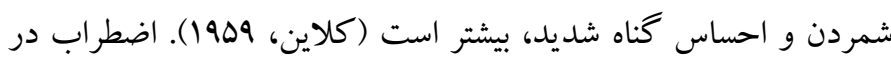
افر اد سالم تنظيم مىشود در حالى كه در افر ادناسالم سر كوب مىشود و و اين

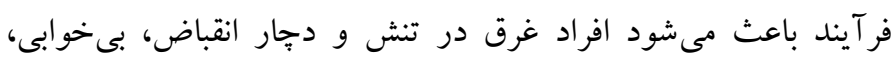

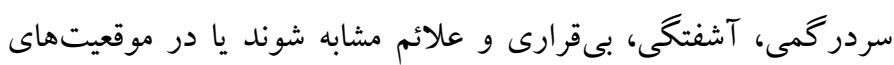

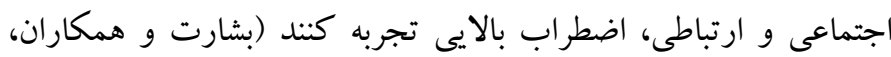

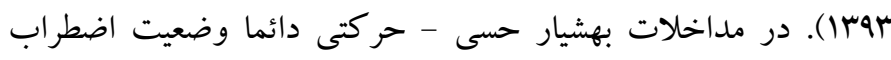

\footnotetext{
1. Intensive Short-term Dynamic Psychotherapy
} 
فر آيندهاى مهم نظم هنده به هيجان اخير ا مورد توجه بسيارى از بثزوهشكران و درمانگران قرار گرفته است.

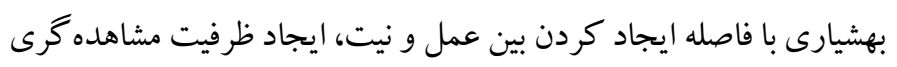

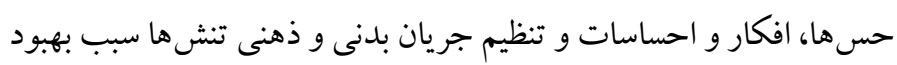

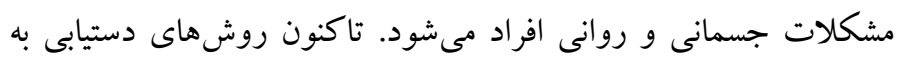

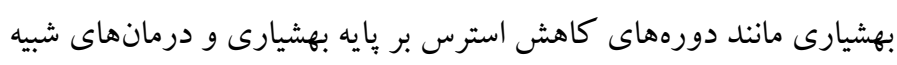

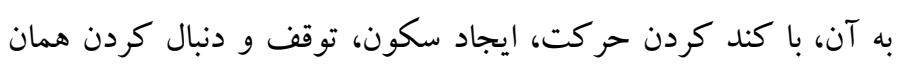

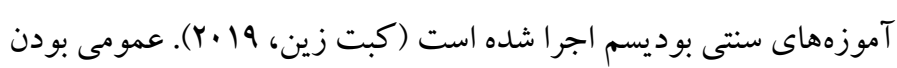
بروتكل دورهها و نه طراحى آن متناسب با ظرفيت ذهنى و بدنى هر فردها

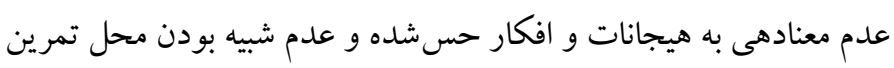

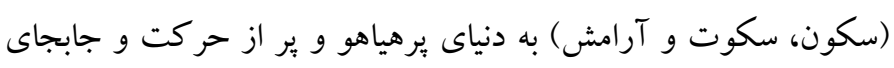

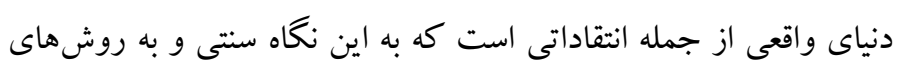

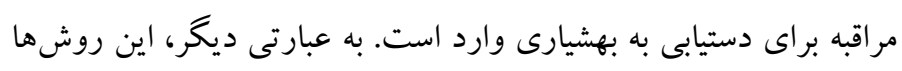
تنها روشى متوسط و دشوار براى رسيدن به تجربه سلامتى هستند (دمارزو

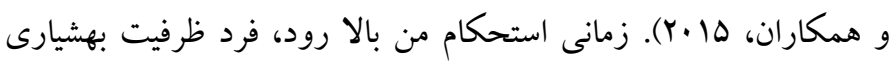

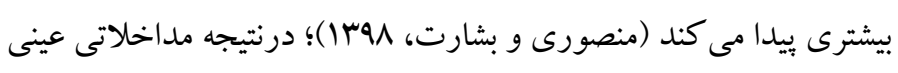
كه روى استحكام ذهن و بدن و بهشيارى همزمان كار كند، مى تواند

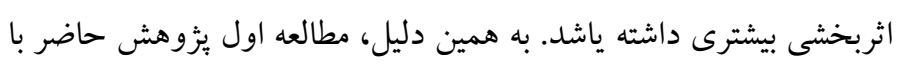

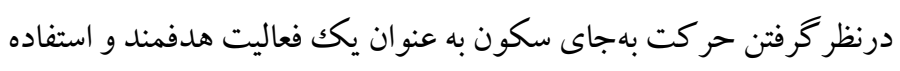

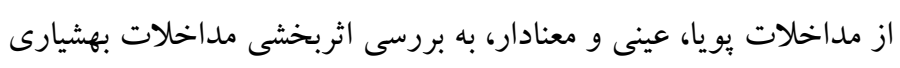

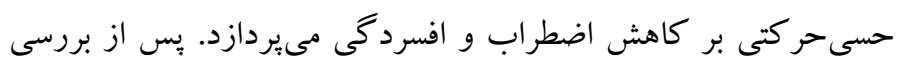

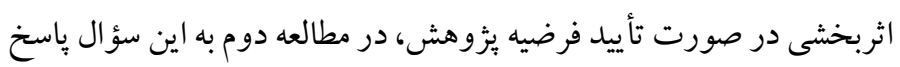

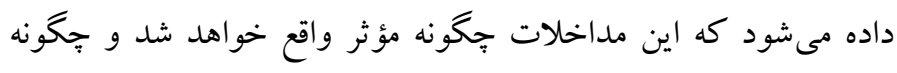

خصيصه هاى شخصيتى منجر به افسردگى و اضطراب را تغيير مىدهد. شكاف بين تشخيص عمق بالينى و تشخيص عينى تا حد زيادى تا به امروز

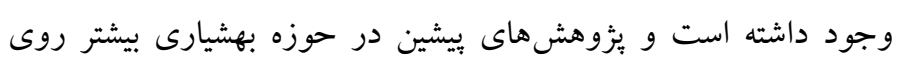

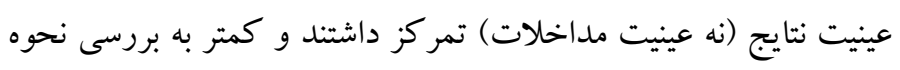

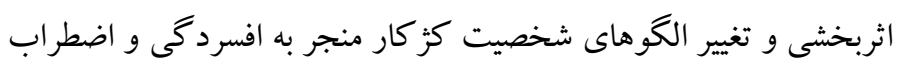

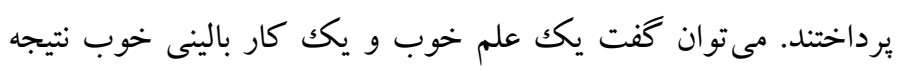

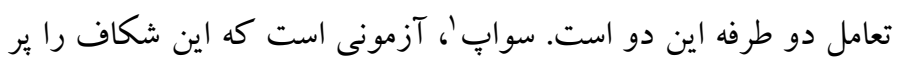
كرده است. آزمون سوابٍ نه تنها نقش قضاوت و هنر بالينى را ناديده نغخرفته
اضطراب خود هشيار و در نتيجه قادر به تحمل هيجانات سركوب شده و بالا رفتن ظرفيت تحمل هيجانى شوند و هنر استفاده كردن از هيجانات را

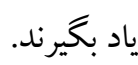
براساس نظريات روانكاوى، افسردگى را مىتوان نشاندهنده خشم

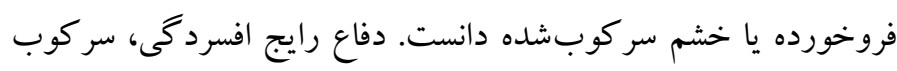

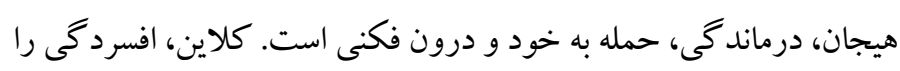

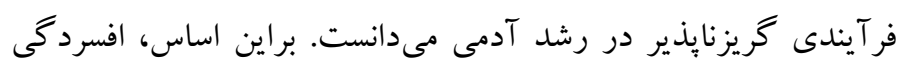

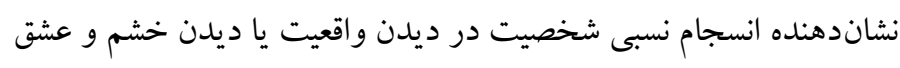

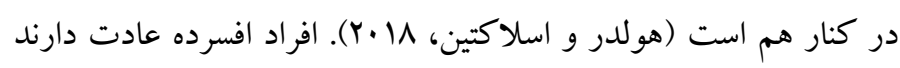
بجاى تجربه خشم، غم را تجربه كنند و اين ناشى از عجزهاى ناسالم اين افراد يا جشم بستن به قدرتهاى واقعى خود است. براساس ديد

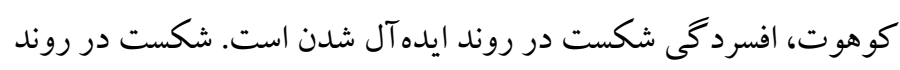
ايدهآل شدن همان شكست در روند معشوق بودن يا موردعشق و توجه قرارگرفتن است (كوهوت، الدهات 191). به همين دليل درمان اساسى افراد

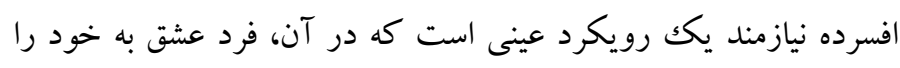
تجربه كند و قادر شود متناسب با واقعيت ادراكك شده، از ظرفيت هاى خود جهت جلب تحسين و بيشرفت استفاده كند. مداخلات بهشيار حسى حر كتى با الكويى از حركت متمر كز بر نظم جويى هيجان، شناساندن دفاعها حين تجربه خشم، ابراز سالم خشم، تقويت استعدادها و توجه سالم به بيمار،

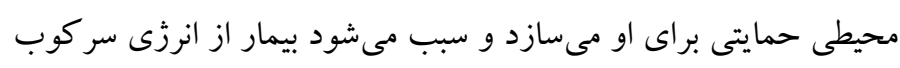
شده خشم منجر به افسردگى در جهت خود آكاهى و واقع بينى استفاده كند

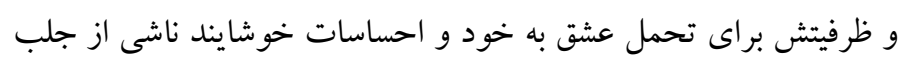
توجه و تحسين متناسب با موقعيت، بالا رود.

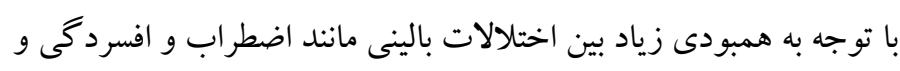
مشكلات شخصيتى، براى درمان افسردگى و اضطراب يكك مدل تلفيقى از زئل

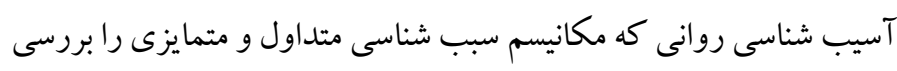
مى كند، ضرورى است. در مطالعات متعددى خصيصه هاى شخصيتى منجر

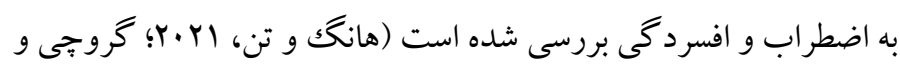

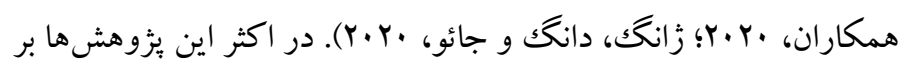
نقش مشكل نظمجويى هيجان به عنوان وجه اشتراك خصيصههاى شخصيت مضطرب و افسرده تأكيد داشتند. بهشيارى به عنوان يكى از ونه از

${ }^{1}$. Shedler-westen Assessment Procedure (SWAP) 
كلينيك مشاوره در تهران بودهاند. نمونه يُزوهش، شامل ·r نفراز افرادى

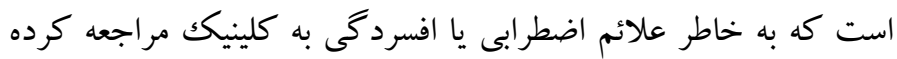
بودند و مشمول دريافت حداقل يكك تشخيص رسمى يكى از مشكلات قرار

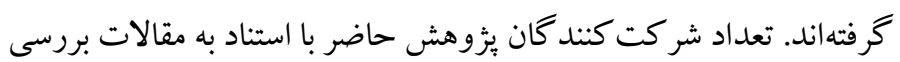
شده در حوزه بهشيارى كه بر اهميت روش كيفى اجراى مداخلات تأكيد

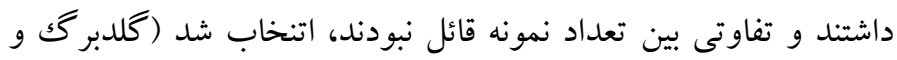

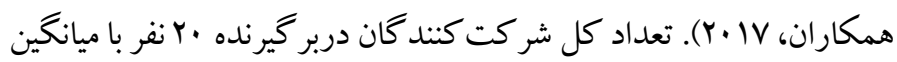

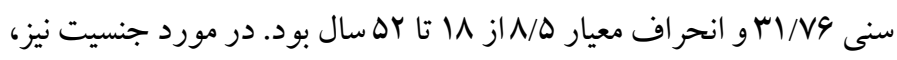

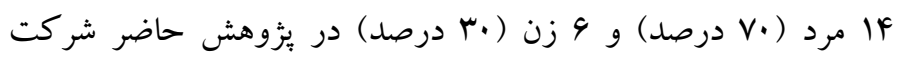

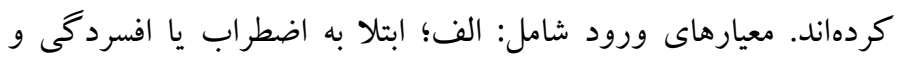
اختلالات مرتبط با آنها (تشخيص توسط ارزياب كلينيك). ب؛ توانايى

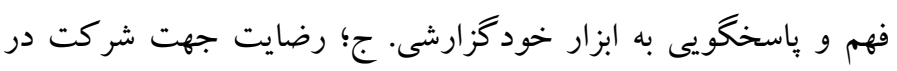
مطالعه و خروج بيماران و معيارهاى خروج شامل بىسو ادى يا عدم تو توانايى

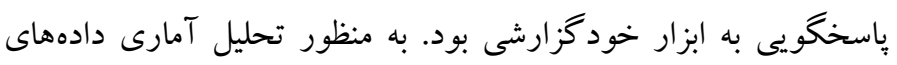

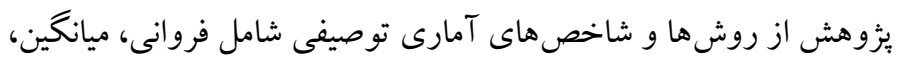
انحراف استاندارد و آزمونهاى آمار استنباطى استفاده شده است. كليه مراحل با بهرهگيرى از نرمافزار آمارى SPSS انجام شده است. مداخلات

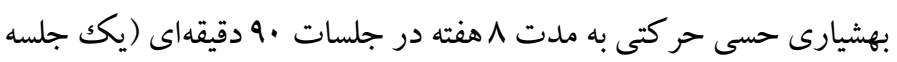
در هر هفته) بر روى نمونه يُوهش اجرا شد. جهت تعيين اثر دوره، در ابتدا

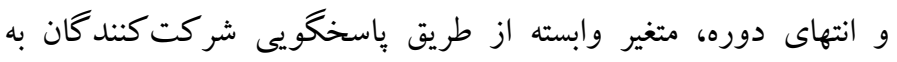

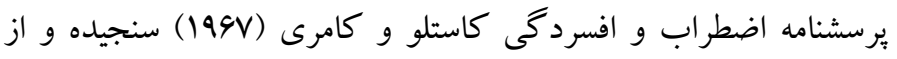
طريق آزمون t زوجى، بيش آزمون و پِ آزمون در گرووه مقايسه شد.

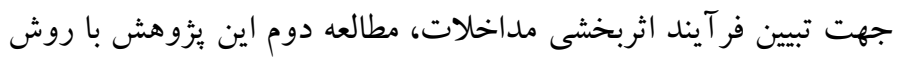

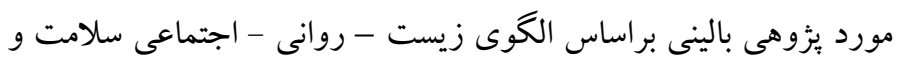

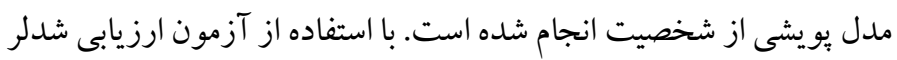
و وستن (سو آب)، شخصيت بيمار و الكوهاى شخصيتى طبيعى در حين و بعد از انجام مداخلات ارزيابى و بررسى شد.
است بلكه با داشتن يك زبان مشخص و واحد تشخيص سبب شده است

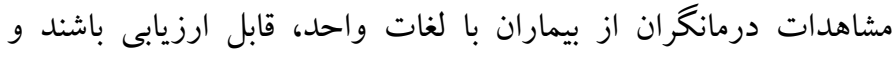

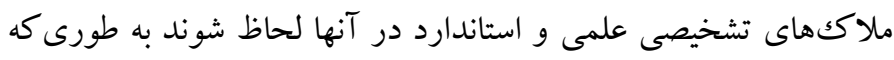

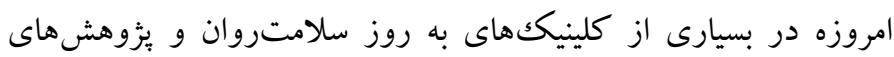

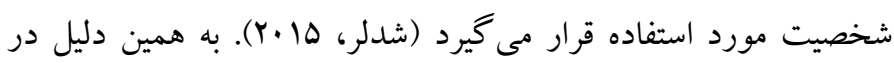
يزوهش حاضر جهت بررسى فر آيند اثربخشى مداخلات از مطالعه كيفى

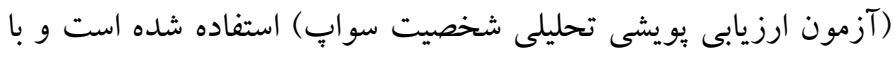

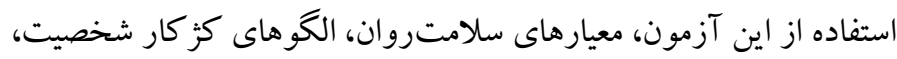

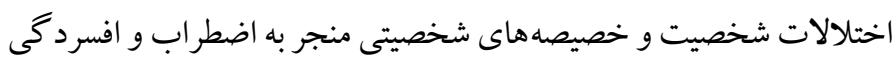
در حين و بعد از مداخلات درمانى سنجيده شد.

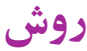
الف) طرح هُوهش و شر كت كنند انان: اين يُزوهش با روش آميخته

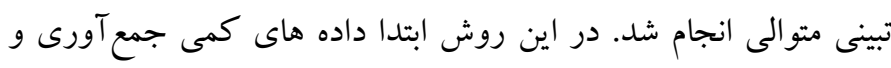

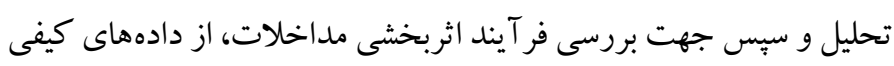
استفاده شد. در اين روش، يافتهاى كيفى به قصد جبران ضعف نتس نتايج

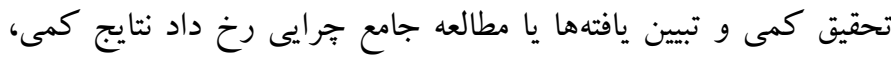

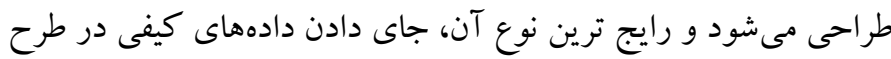

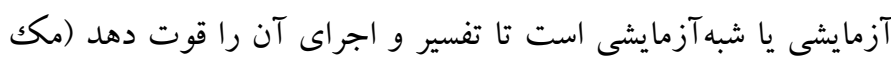
كيم، Y.IV) جهت ارزيابى شخصيت، ارزيابى تنظيم هيجانى، سلامتروانى و اختلالات بيشبينى كنده اضطراب وافسردگى است. مدت زمان مصاحبه هـ ه - . 1. ساعت است و در قالب سنجش هشيار و ناهشيار علائم زيستى، روانى و

$$
\text { ارتباطى مراجع، اجرا مىشود. }
$$

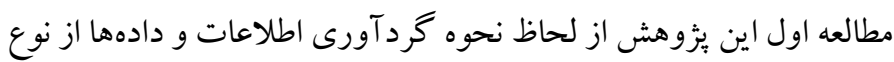
شبه آزمايشى و از نظر هدف، از نوع تحقيقات كاربردى مىباشد. مداخلات درمانى بهشيار حسى - حركتى در طول مدت ^ هفته (يكك جلسه •9 دقيفه

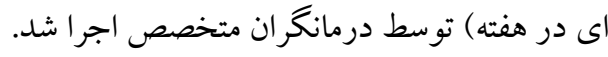
جامعه آمارى مورد بررسى اين يُزوهش در مطالعه دوم شامل تمام افراد

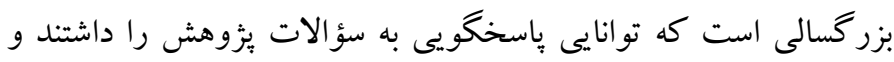
آماده به همكارى در ويشبرد اهداف يُزوهش بودهاند. انجام يزٔهش در شهر ئر

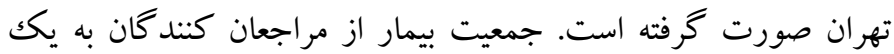




\section{جدول ا. التوى زيستى روانى اجتماعى مداخلات بهشيار حسى حركتى، (كاشانكى و همكاران، ..ع 1)}

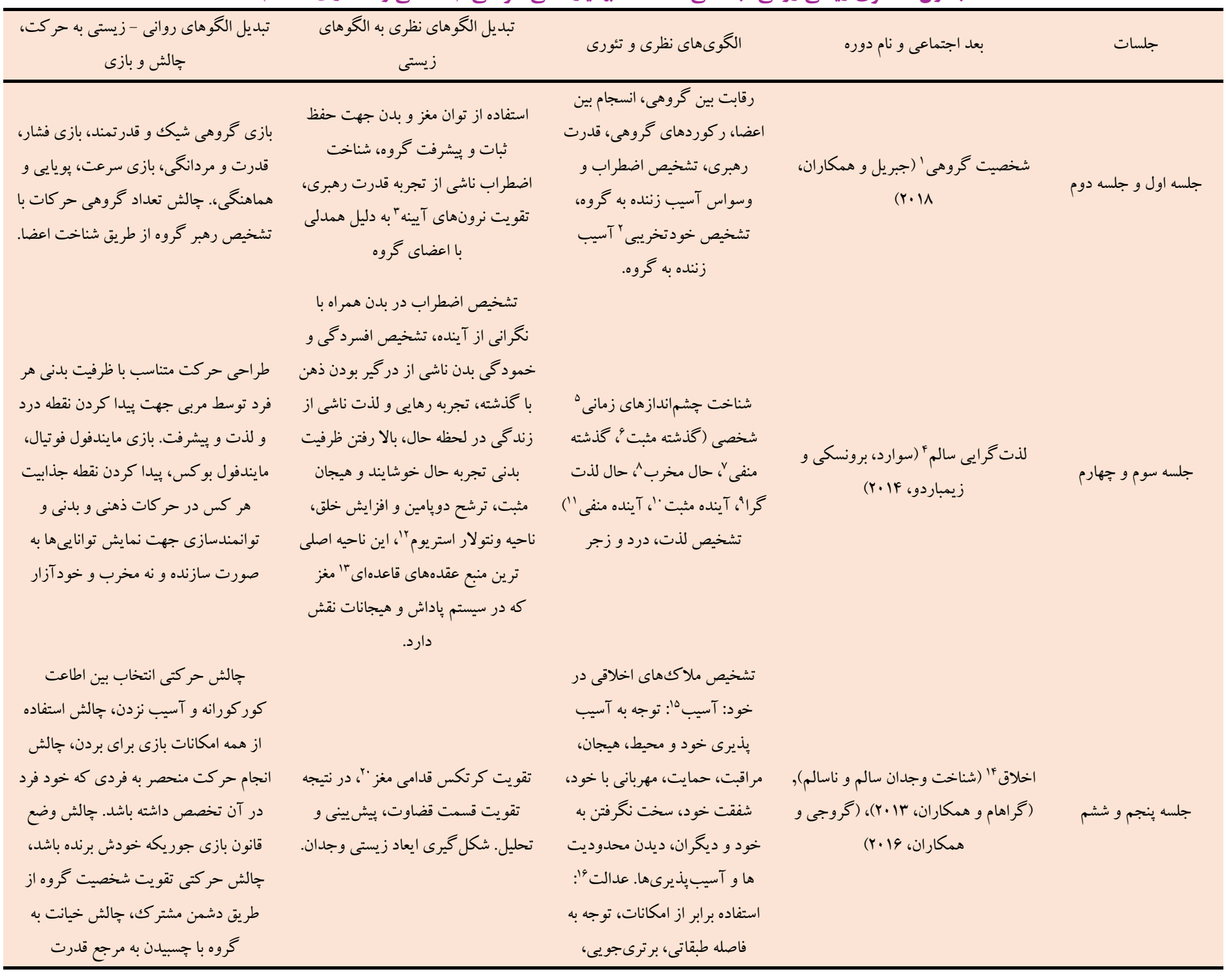

1. Group Personality

2. Self-Destructiveness

3. Mirror neuron

${ }^{4}$. Healthy Hedonistic

5 .Time Perspective

6. Past-Positive

7. Past-Negative

${ }^{8}$. Present Fatalistic

9. Present Hedonistic

${ }^{10}$. Future Positive

11. Future Negative

12 . ventral striatum

13. Basal ganglia

14. Moralism

15. Harm

16. Fairness

17. Prefrontal Cortex 


\begin{tabular}{|c|c|c|c|c|}
\hline تبديل الكوهاى روانى - زيستى به حركت، & تبديل الكوهاى نظرى به الخوهاى & الكوىهاى نظرى و تئورى & بعد اجتماعى و نام دوره & جلسات \\
\hline 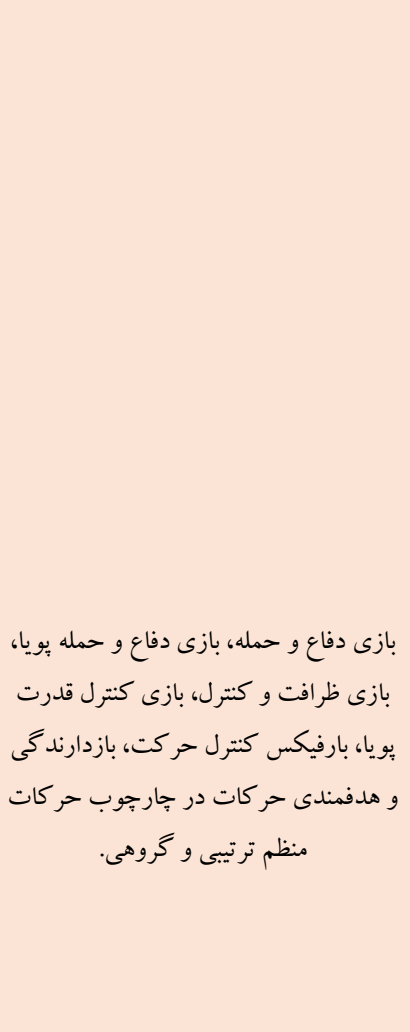 & تصويت & 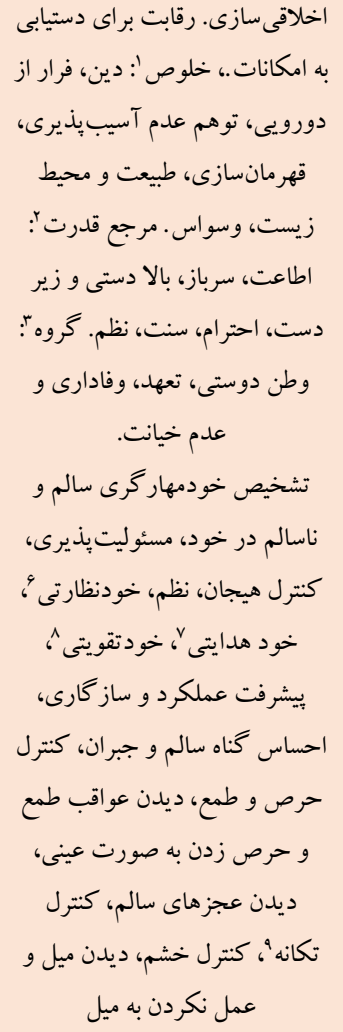 & خودمهار گرى (مامايك،، پاترنوستر و & جلسه هفتم و هشتم \\
\hline
\end{tabular}

ذكر شده است. در اين مداخلات، تئورىهاى درمانى به روز، به عمل تيديل شده است و در قالب حر كت و بازى آموزش داده شد.
براساس جدول ا، مداخلات بهشيار حسى حر كتى دربر گيرنده مداخلات مدون انسجام بخش ذهن و بدن و حر كت ها و بازىهاى نوين براى آكاهى به خصيصههاى شخصيتى مؤثر و دستيابى به سلامتروان است. اين مداخلات در f بعد شامل خودمهار گرى، اخلاق، لذت گرايى سالم و شخصيت كروهى طبقهبندى شدهاند. هر بعد از مداخلات همراه با زيربناى نظرى زيستى، روانشناختى و تبديل آنها به حركت و جالش در جدول

\footnotetext{
1. Purity

2. Authority

${ }^{3}$. Ingroup

5. Self-Control

6. Self-Monitoring

7. Self-directed

${ }^{8}$. Self-Reinforcement

${ }^{9}$. Impulse Control

${ }^{10}$. Brodmann area

11. Insula

12. Temporal
} 
جدول r. مثال درمانى از مداخلات بهشيار حسى حر كتى

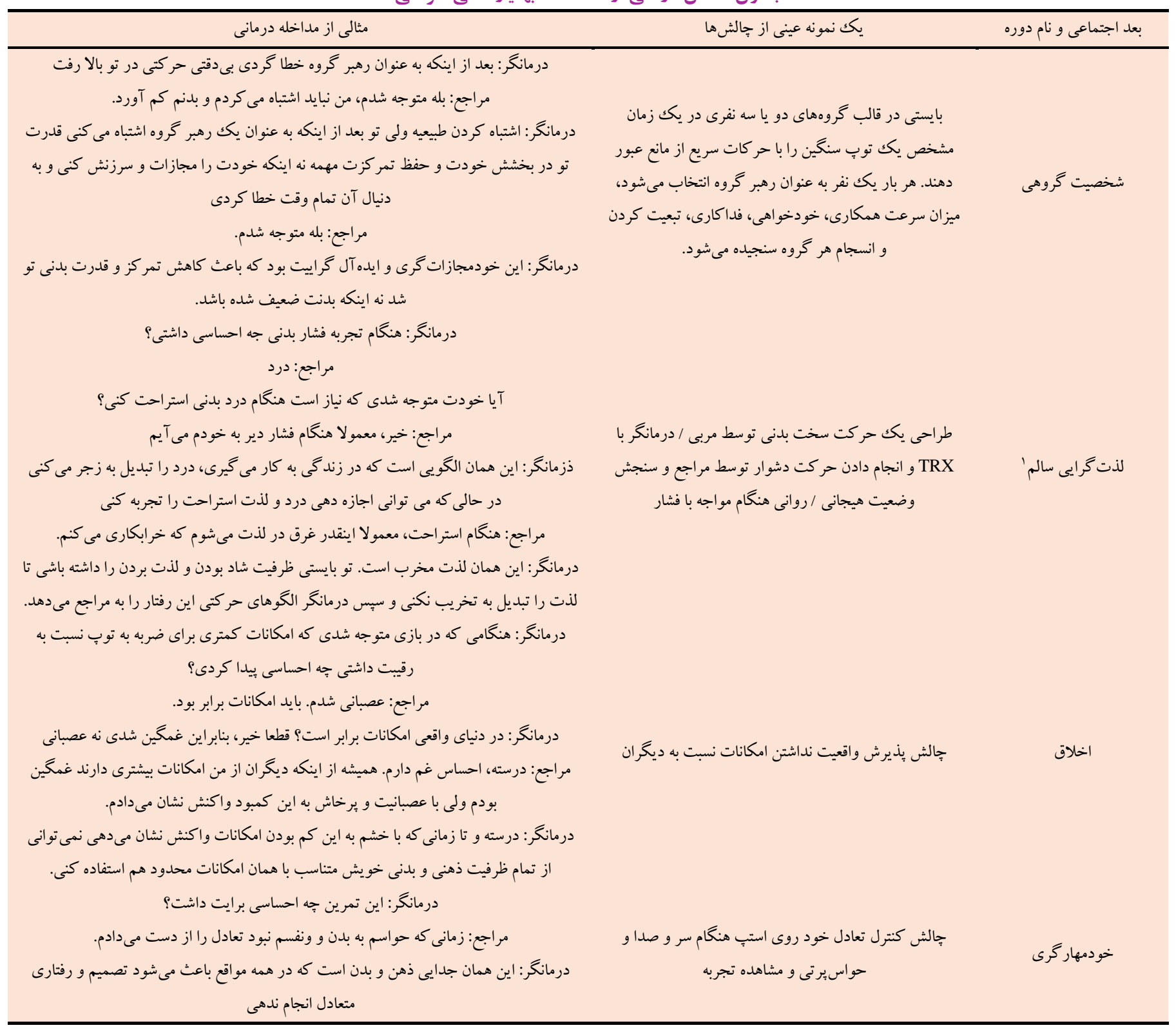

\begin{tabular}{|c|c|c|c|}
\hline احساسات متضاد و نفرت سر كوب شده بالا، & 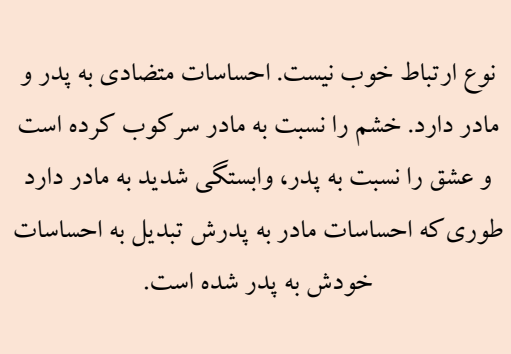 & 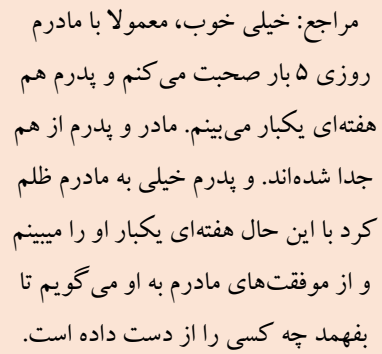 & درمانكر: نوع ارتباطت با اعضاى \\
\hline
\end{tabular}

\section{${ }^{1}$. Healthy Hedonistic}


كدگذارى آنها در قالب متغيرهاى شخصيت به روز و اثر كذار در حوزه

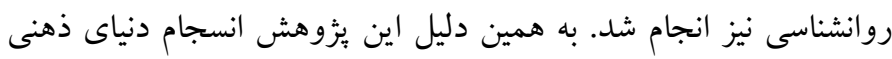

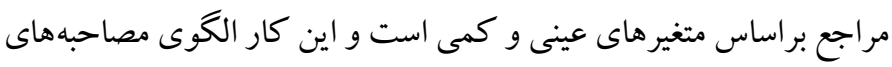

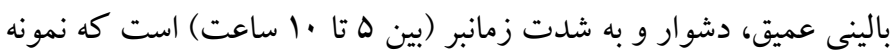

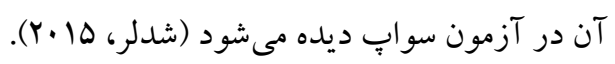

مصاحبه شخصيت سو آب تمامى زواياى نظرى و بالينى جهت توصيف

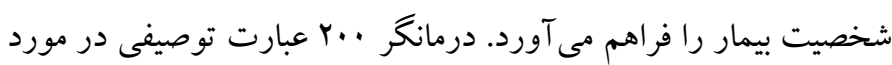

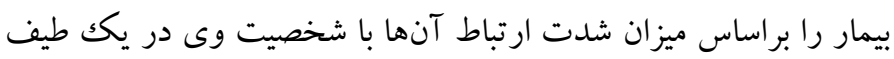

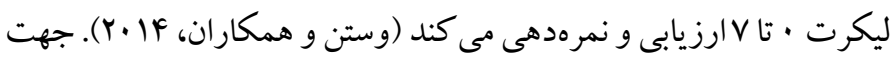

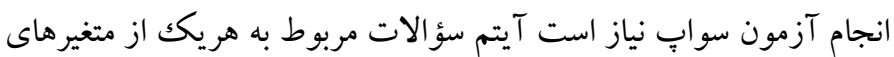

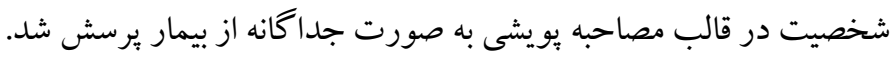

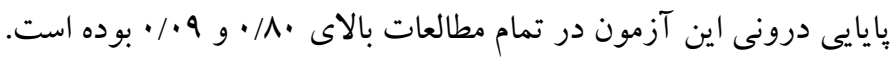

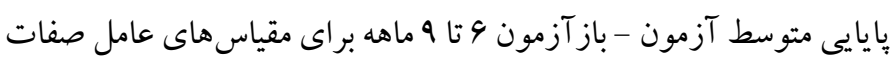

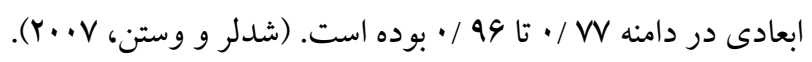
در اين يزؤهش از مصاحبه عميق يويشى استفاده شده است. مصاحبه يويشى

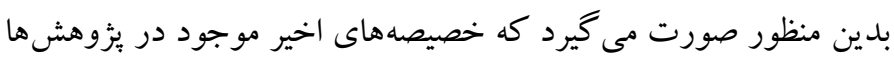

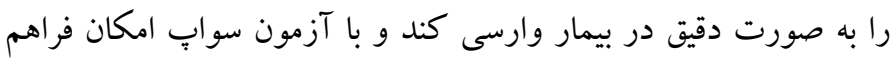
كردن يكك توضيح جامع، جند بعدى، استاندارد، عميق و كمى بر ايى سنجش ونش

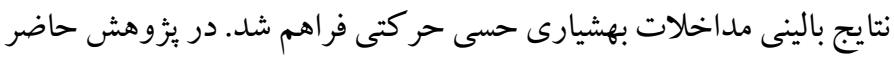

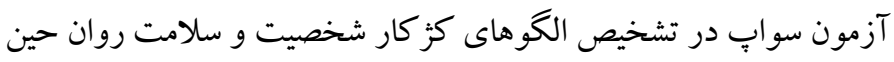

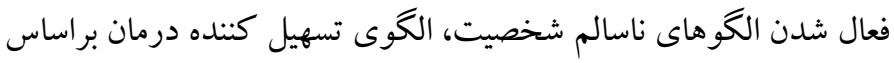

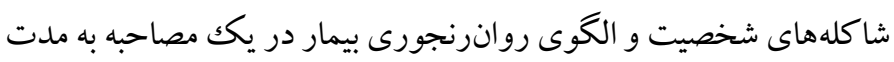

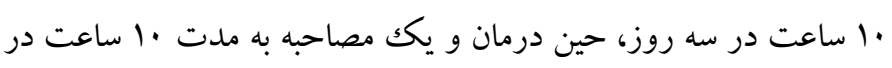

$$
\text { سه روز بعد از درمان سنجيده شد. }
$$

يافته ها

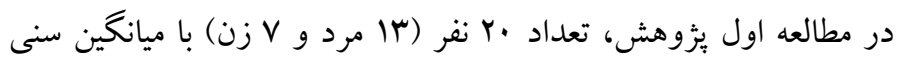

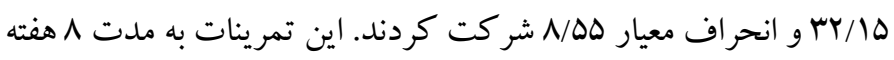
در جلسات •و دقيقهاى (يكك جلسه در هر هفته) اجرا شد. جهت تعيين اثر

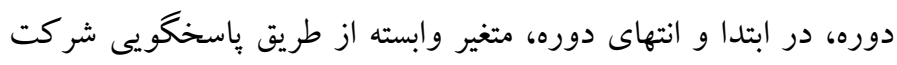

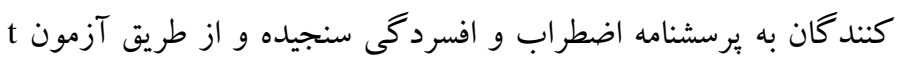
زوجى، بيش آزمون و بِ آزمون مقايسه شدند.
در جدول r، نمونه و مثال جالش بهشيار هر سبكك و مداخلات درمانى مرتبط با آنها ذكر شده است. همانطور كه در جدول مشاهده مىشود؛ مداخلات بهشيار حسى حركتى، سبكى از جالش، حركت و مداخلات

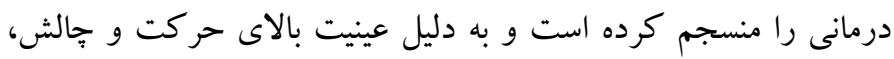
درك مداخلات درمانى در اين رويكرد، براى مراجعين سادهتر است.

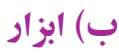
مقياس افسردگى و اضطراب (كاستلو و كومرى، 199V): اين مقياس سج

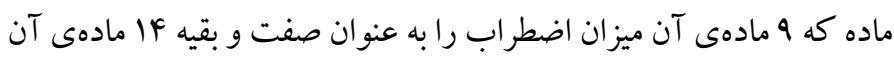

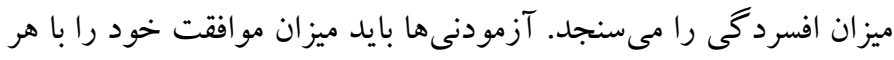

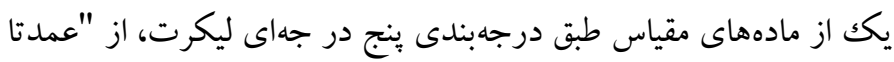

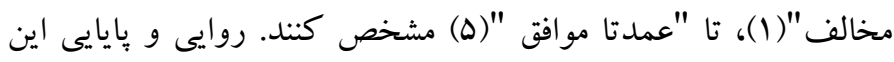

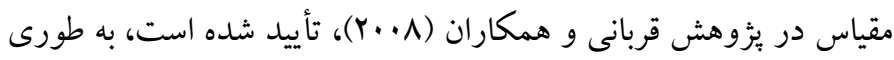

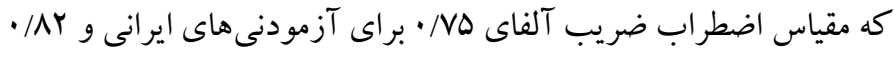

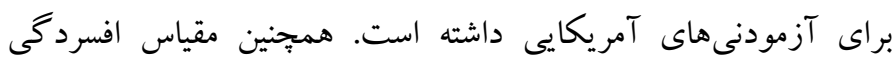

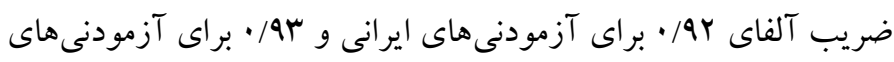
آمريكايى نشان داده است.

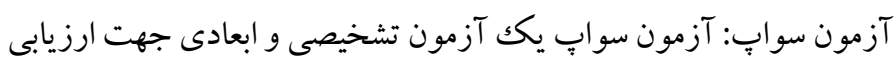
طيف وسيعى از مشكلات روانشناختى، اختلالات شخصيت و سلامتروان است. تمام آيتمهاى سواب از طيف گستردهاى از منابع ادبيات بالينى

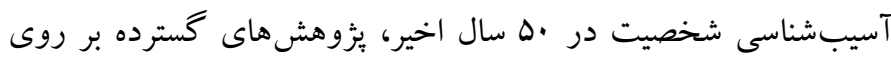

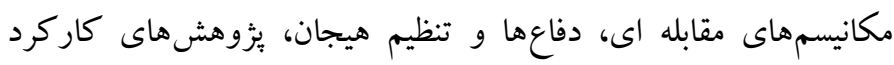
بين فردى در افراد داراى اختلالات شخصيت و خصيصههاى شخصيتى در

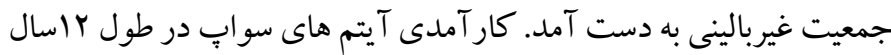

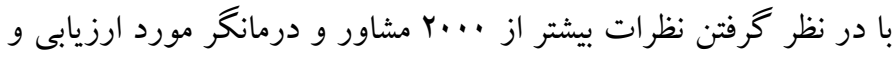

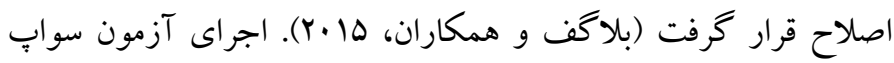

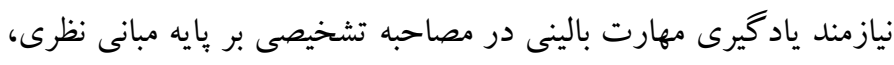

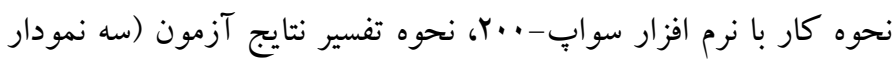

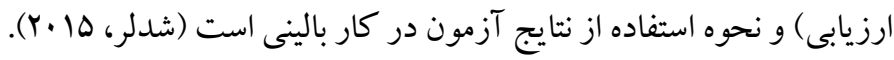
اين روش در بِاسخ به بيشبينى كم و عدم كاربردى بودن اطلاعات

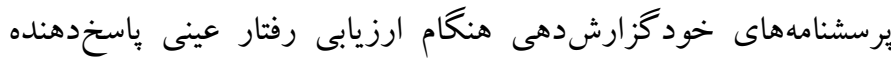
ايجاد شده است. اين روش در برسيدن سؤالات شخصى از مراجع و ورسئ 
نرمالى هستند و مى توان از تحليلهاى بِارامتريكك براى آن استفاده كرد.

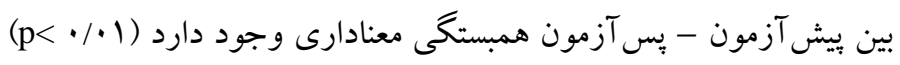

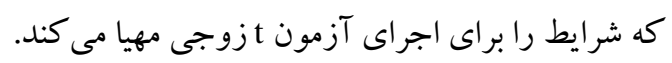

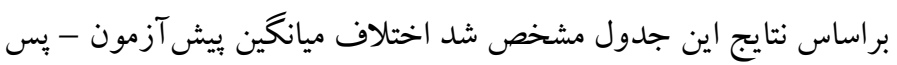

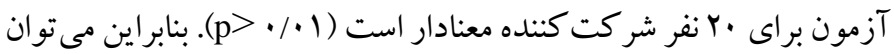

$$
\text { كفت مداخلات سبب كاهش اضطراب مى شود. }
$$

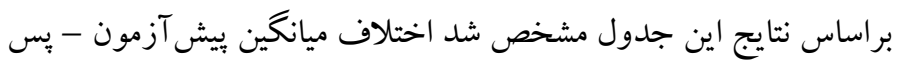

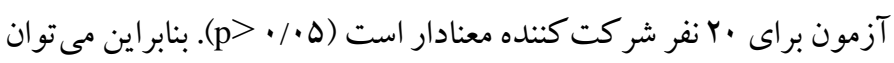

كفت مداخلات بهشيار حسى حر كتى سبب كاهش افسرد گى مى شود.

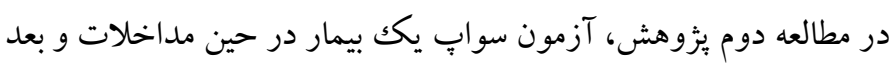

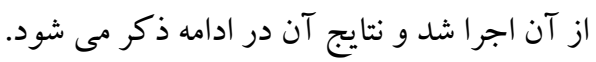

جدول ا. ميانكين و انحر اف معيار سن شركت كنندكان

\begin{tabular}{|c|c|c|}
\hline تعداد & انحر اف معيار & ميانگين \\
\hline$r$. & $\Lambda / \Delta \Delta$ & $r Y / l Q$ \\
\hline
\end{tabular}

در جدول ه ميانگين، انحراف معيار و آلفاى كرونباخ مربوط به مقياسها

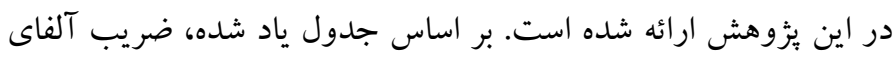

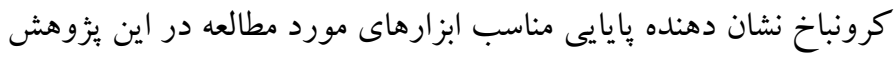

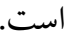
قبل از اجراى آزمون t، ييشفرضهاى انجام اين آزمون بررسى مىشود.

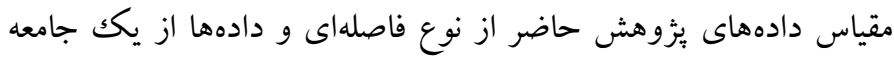
واحد به دست آمده است.

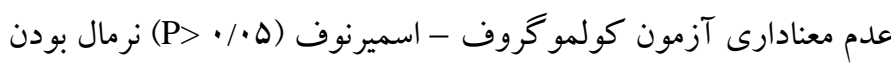
توزيع دادها را نشان مىدهد. بنابراين هر سه متغير وابسته داراى توزيع

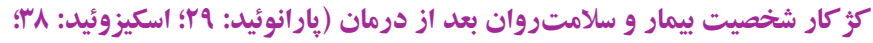

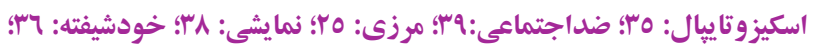

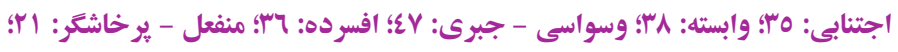

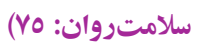

همانطور كه در شكل مشخص است، تمام الخوهاى كز كار شخصيتى بيمار بعد از درمان يايين آمدهاست و سلامتروان بان بالارفته است. براساس شكل rا، شاكله شخصيت بيمار تغييراتى اساسى كرده است.

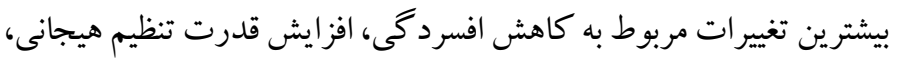
سلامتروان و كاركرد ذهنى و بدنى بوده است.

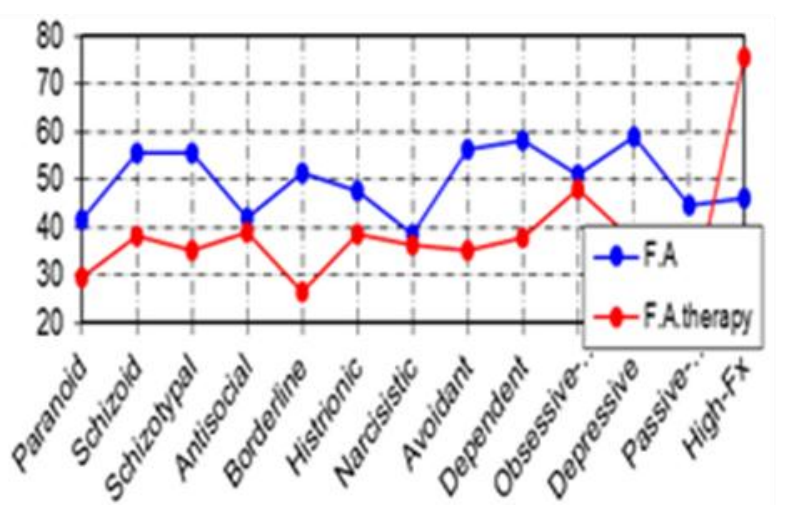

شكل ا. مدل تشخيصى الكوهاى كز كار شخصيت بيمار و سلامتروان حين درمان

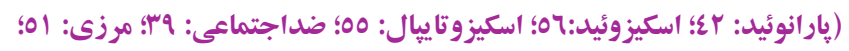

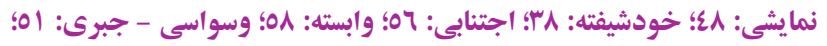

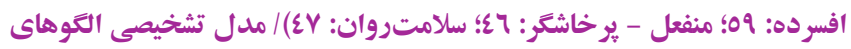


شدن تجربههاى زندگى و ظرفيت عشقورزى است. همجنين بدكاركردى

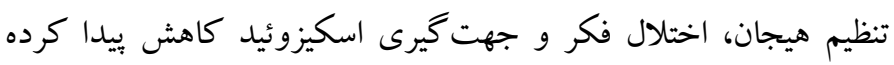

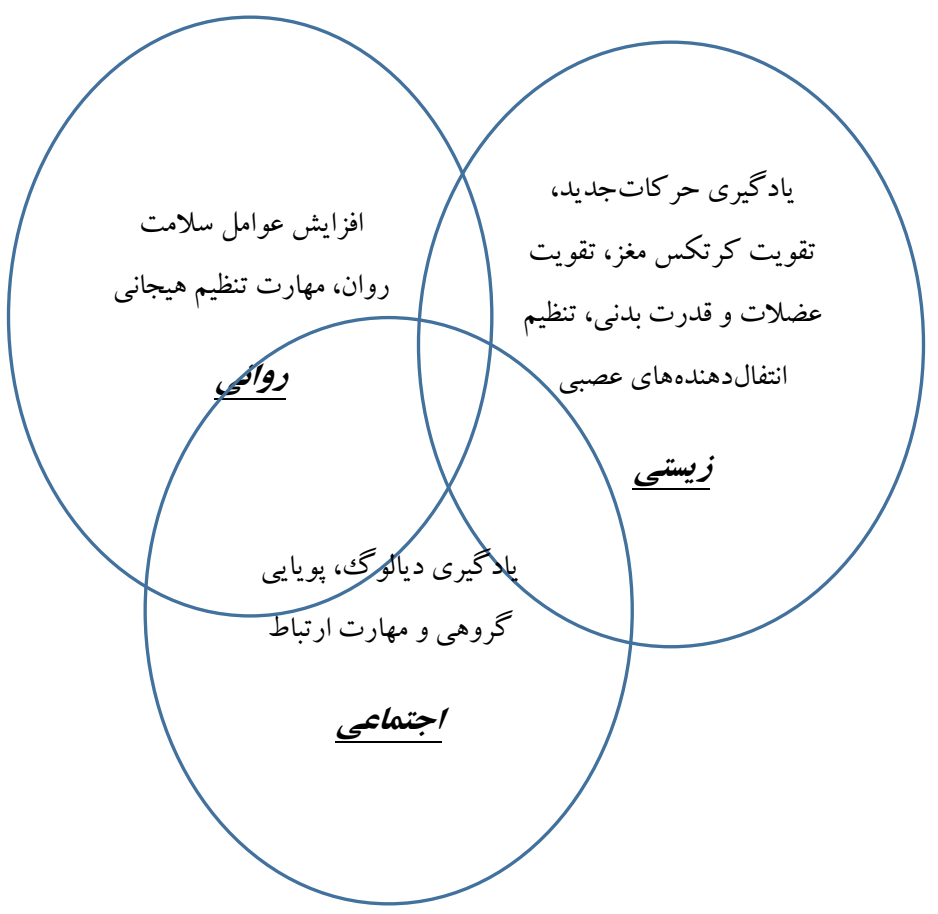

شكل ع. تبيين فر آيند اثربخشى مداخلات براساس رويكرد روانشناسى سلامت (زيستى - روانى - اجتماعى)

\section{بحث و نتيجه كيرى}

نتايج اين بزوهش نشان داد كه مداخلات بهشيار حسى حر كتى تغيير اتى در

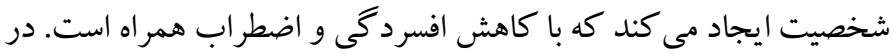

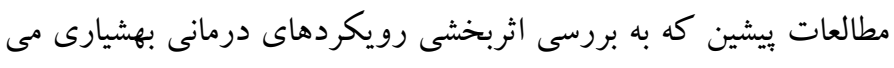

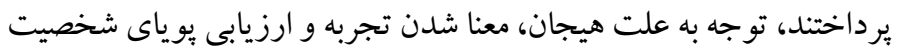
وجود نداشت و تمامى اين رويكردها همان آموزههاى سنتى بودا را در برد

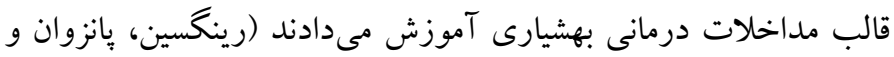

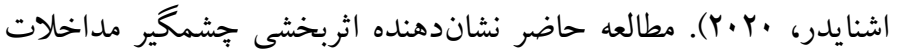
بهشيار حسى حر كتى بر اضطراب بود. به عبارتى ديخر، مداخلات بهشيار حسى حر كتى طورى طر احى شدهاند كه افراد فر آيند هشيار و ناهشيار تنظيم

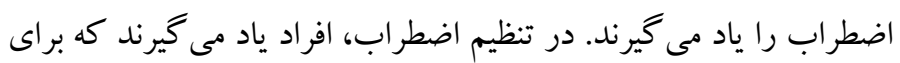
حفظ تعادل، تداوم قدرت، حفظ توجه و تمركز و حفظ ظرافت و تيزبينى، نيازمند توجه بدن هستند. جدايى ذهن از بدن همان وضعيتى است كه در

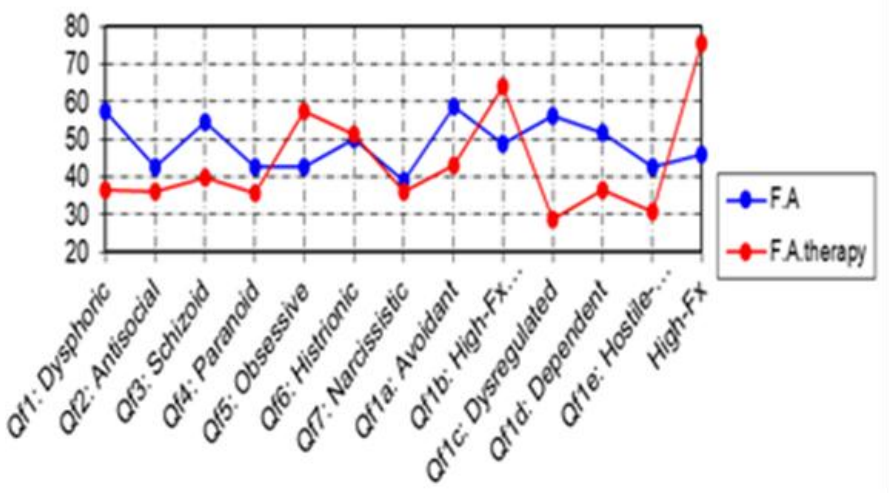

شكل ז. توصيف الكوى تسهيل كننده درمان بر اساس شاكله شخصيت بيمار حين

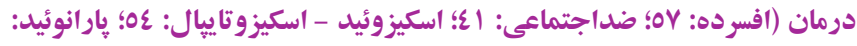
r

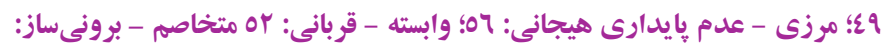

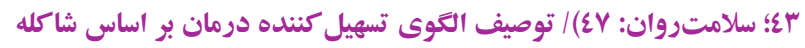

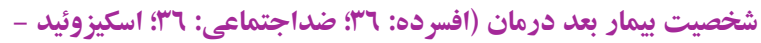

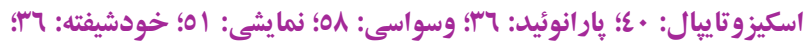

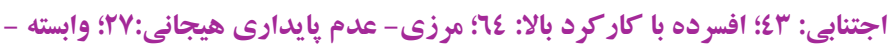

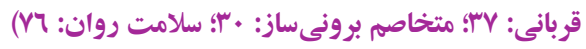

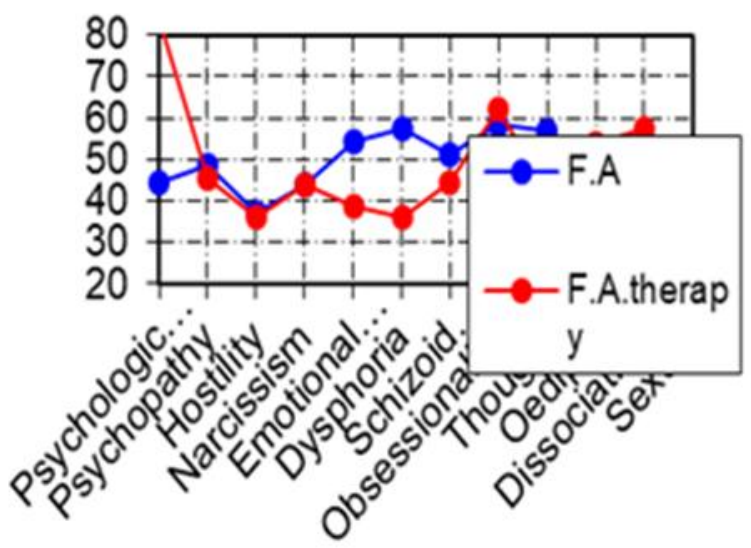

شكل ". الكوى روانر نجورى بيمار بر هايه شخصيت حين درمان (سلامتروان: عـ؛؛

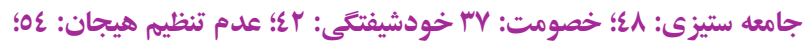

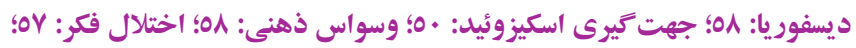

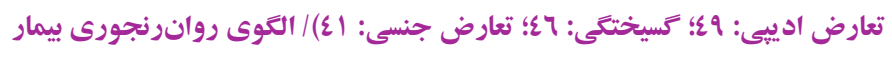

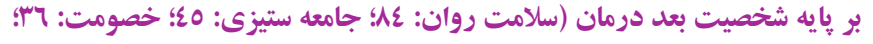

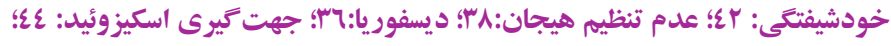

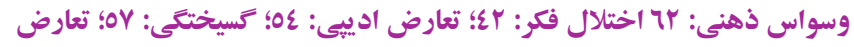

جنسى: (ع)

براساس شكل سا، افزايش شاخص عينى سلامتروان بعد از درمان رخ داده

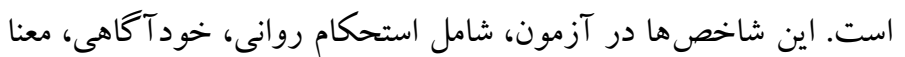


حتى بعد از اتمام طول درمان، باز هم بهبودى را تجربه خواهد كرد

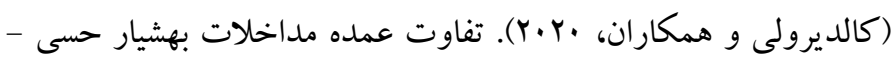
حر كتى تمر كز بيشتر بر مداخلات عينى مانند فعاليت بدن و حركت بجاى مداخلات ذهنى است درنتيجه در مداخلات بهشيار حسى - حر كتى ميزان دروغهايى كه كه مراجع به خود و درمانخر مى گويد تا حد زيادى كاهش ييدا مى كند. در اين مداخلات، بازسازى كانالهاى بدنى اضطراب و هيجان سريعتر بازيابى مى شوند و همزمان مداخلات درمانى هم توسط درمانكر ارائه خو اهد شد. زمانيكه حافظه بدنى فعال مى شود احتمال فراموشى اين مداخلات تقريبا به صفر مىرسد. در نتيجه مداخلات هيجانمدار روان درمانى بويشى در يكك فضاى حسى حركتى با جارجّوب اجتماعى كه هر دوره دارد، يكك رويكرد درمانى منسجم زيستى روانى اجتماعى را مىسازد كه نتيجه آن اثربخشى جشمخير بر كاهش اضطر اب، افسردگى و شكوفايى استعدادهاى ذهنى و بلنى است. مطالعه دوم يزووهش حاضر نشان داد اين روش درمانى، قادر است شخصيت بيمار و كز كار را به سمت يكك شخصيت منسجم و سلامت تغيير دهد. ساختار شخصيتى بيمار از يكك شخصيت اجتنابى، منزوى، كوشه كير و افسرده تبديل به يكك فرد دقيق، منظم، وظيقهشناس و با كاركرد بالا تغيير كردهاست. تغيير الكوهاى شخصيتى افزايش دهنده ريسك اضطراب و افسردگى سبب مى شود خشم فروخورده در بازىها معنا و تنشها تبديل به حركت و كشف استعدادها مى شود. همجنين بازىهاى حسى - حركتى مى تواند منجر به مهارت حل مسأله خلاق شود و همسو با بثروهشى است كه نشان داد حل مسئله خلاق با كاهش افسردگى همر اه مى شود (ارشادى

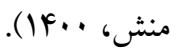
تغير الكوهاى تنظيم هيجانى در اين بيمار مشهود است. اين تغيير نقش اساسى يادگيرى مهارت تنظيم هيجانى آموزش داده شده مداخلات را در تغيير ساختار شخصيت را نشان مىدهد. درمان اختلال شخصيت وابسته و اجتنابى، درمان علائم افسردگى، مشكلات تنظيم هيجانى و نايايدارى خلق و افزايش معنادار سلامتروان از نتايج مطالعه كيفى ثئوهش حاضر است. يثزوهش هاى ييشين معمولا به يكك ئزوهش كمى اكتفا مى كردند و كمتر به بررسى فر آيند تغيير مى برداختند. به عنوان نمونه فومرو و همكاران ( ·. (Y) در يكك فراتحليل كسترده نشان دادند بزووهش هاى جديد حوزه بهشيارى براى تبين اثربخشى مداخلات بهشيارى نياز است سلامت، خود آكاهى و
اين مداخلات دائم بررسى مى شود و فرد ياد مى گيرد كه در طول تمام حركات و بازى ها، ذهن را در بدن نخه دارد و همين كليد اثربخشى جشمخير اين مداخلات بر كاهش اضطراب است. در اكثر يثزوهشهاى بيشين كه بر روى اضطر اب انجام شده بود، اضطر اب را به عنوان يكك عامل مخرب در نظر مى گرفتند (سعيد، كانينگهام و بلاخ، 19 •.ب)؛ در حالى كه در مداخلات بهشيار حسى - حر كتى اضظراب نشانه وجود يك تعارض است كه هر لحظه در طول جلسه بررسى و علت زيربنايى آن شناسايى مىشود. مربى يا درمانكر با استفاده از مداخلات بهشيارى حسى حر كتى، نيمكره راست را فعال مى كند؛ فعالسازى كنترل شده نيم كره راست مغز، هيجانات سر كوب شده را بيدار و سيس مربى يا درمانكر آنها را معنا مى كند؛ اين سبكك از معنا كردن، انسجام دو نيم كره مغز را رقم مىزند. بر اساس يثوهش هاى اخير، روشى كه بتواند هيجانات نيمكره راست را به شكل كنترل شده بيدار و معنا كند از به روزترين و كاربردى مداخلات درمانى

هيجانمدار شناخته مىشود (شور، ·r.r). مداخلات بهشيار حسى - حر كتى با تغيير الكوهاى كز كار شخصيت سبب كاهش افسردگى در مراجعين شد. افسردگى زمانى درمان مىشود كه هيجانات بازدارى شده و استعدادهاى فرد، سركوبزدايى شود (تون و همكاران، .Y.Y). زمانيكه ذهن و بدن منسجم مىشوند، فرد مى تواند انرزىهاى بازدارى شده را آزاد كند. در اينجا قوانين بازىها و حر كات اين انرزى ها را به سمت سازندكى سوق مى دهد و همين كليد درمان و اثربخشى ستى مداخلات بر افسردى است. تحقيقات بلند مدت بر روى رواندرمانىها خصوصا رواندرمانىهاى شناختى معمولا نشان دادهاند كه افسردكى و اضطراب هر دو بعد از تمام شدن طول درمان، دوباره رخ خواهند داد (تون و همكاران، ·r.r.Y)؛ در حاليكه مداخلات بثزوهش حاضر با ديدن انرزى نهفته يشت افسردكى و اضطراب، آنها را جهت خودشكوفايى و بهبودى به كار مى گيرد و همين تفاوت مداخلات سر كوبزدا با مداخلات سركوب كننده است. سركوب زدايىهاى بدنى همان مسئلهاى است كه در يزووهش هاى بلند مدت حوزه اضطراب و افسردگى موجب درمان خواهد شد (ير ينس و همكاران، ·.r.r). از بين رويكردهاى درمانى، مداخلات رواندرمانى بويشى فشرده كوتاه مدت بيشترين شباهت را به مداخلات بهشيار حسى حركتى دارد. اين مداخلات جزو معدود درمانهايى هستند كه ماند كارى بالايى دارند بيمار 
براساس نظريات اخير حوزه بهشيارى هر روشى كه انسجام ذهن و بدن را رقم بزند، مىتواند رويكردى درمانى مبتنى بر بهشيارى شناخته مىشود

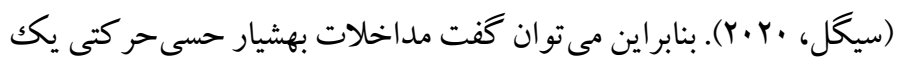
رويكرد درمانى مبتنى بر بهشيارى است كه با كاهش محسوس اضطراب و افسردكى همر اه مى شود و سلامتروان و انسجام ذهن و بدن را رقم مىزند؛ با اين وجود، براى تبديل شدن به يكك رويكرد جهان شمول و منسجم راه زيادى در ييش دارد و مطالعات كيفى و كمى بيشترى با تعداد نمونه بالا و متنوع نياز است.

ملاحضات اخلاقى هييروى از اصــول اخلاق يخوهش: اين مقاله بركرفته از رساله دكترى نويسنده اول

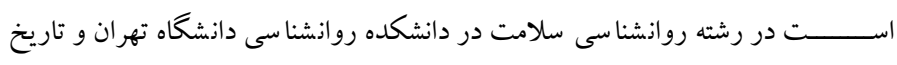
تصويب يرويوزال QM/II/IF است. حامى مالى : اين يزّوهش در قالب رساله دكترى و بدون حمايت مالى مىباشد. نقش هر يكك از نويسند كان: نويسنده اول محقق اصلى اين يزوهش است. نويسندكان دوم و سوم استاد راهنما و نو يسنده جهارم استاد مشاور رساله مىباشند.

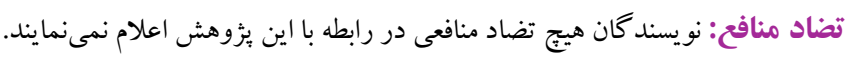
تشـكر و قدردانى: بدين وسيله از اساتيد راهنما و مشاوران اين تحقيق و نيز مراجعين كلينيك روانشناسى كه در انجام اين تحقيق يارى نمودند، تشكر و قدردانى مى گردد.
يذ يوش خود' رادر مراجعين بررسى كنند و در نظر گرفتن سالامتروان و خوداكاهى سرعت بهبودى را بالا مى برد. نتايج بزوهش حاضر نشاندهنده

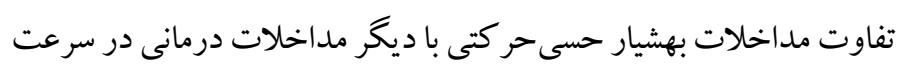
اثربخشى درمان اختلالات است. اين اثربخشى از طريق آموزش عملى حسى حركتى مهارت خودآكاهى هيجانى و تنظيم هيجانى رخ داد. مهارت هاى تنظيم هيجانى نقش اصلى را در تأثير مداخلات درمانى دارند. اين نتايج همسو با يُوهشهاى در ارتباط با نقش واسطهاى فر آيندهاى تنظيم هيجانى در ارتباط خصيصه هاى شخصيت و سلامتروان است

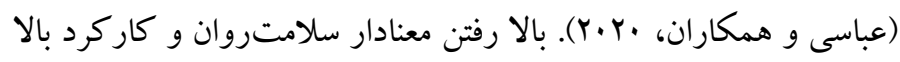
حين افسردگى نشان مىدهد اين مداخلات، ظرفيت را براى تحمل افسردكى بالا مىبرد و به جاى اينكه فرد غرق در غم ناشى از ديدن واقعيتها شود سعى مى كند در غم واقعيتها شنا و دستاوردهاى جديدى كسب كند. بالا رفتن استحكام روانى، خود آكاهى، ظرفيت عشقورزى و معنا شدن تجربهها از ديخر اثرات منحصر به فرد اين مداخلات بود. به طور كلى نتيجه مطالعه دوم نشان داد مداخلات بهشيار حسى حركتى نه تنها اختلالات را درمان مى كند بلكه ظرفيت فرد را براى شكوفاسازى استعدادها و رسيدن به بالاترين حد بهرهورى، بالا مى برد.

1. Self-Acceptance 


\section{References}

Abbasi, M., Ghorbani, N., Imani, A. H., \& Tahbaz Hoseinzadeh, S. (2020). Exploring the mediating role of integrative self-knowledge in the relationship between mindfulness and well-being in the context of a mindfulness-based stress reduction program. International Journal of Psychology.56 (2), 249-256. DOI: 10.1002/ijop.12705. [Link]

Abbass, A., Town, J., Holmes, H., Luyten, P., Cooper, A., Russell, L., ... \& Kisely, S. (2020). Short-term psychodynamic psychotherapy for functional somatic disorders: a meta-analysis of randomized controlled trials. Psychotherapy and Psychosomatics, 89(6), 363-370. DOI: 10.1159/000507738. [Link]

Baumeister, R. F., \& Vohs, K. D. (2016). Strength model of self-regulation as limited resource: Assessment, controversies, update. In Advances in experimental social psychology.54,67-127..Doi: 10.1016/bs.aesp.2016.04.001. [Link]

Besharat M, Masoudi M, Dehghani S, Motahari S, Pourkhaghan F. (2014). Social anxiety symptoms and anger: The mediating role of emotion regulation difficulties. Journal of psychological science, 13(51). 321-339. (Persian). [Link]

Caldiroli, A., Capuzzi, E., Riva, I., Russo, S., Clerici, M., Roustayan, C., ... \& Buoli, M. (2020). Efficacy of intensive short-term dynamic psychotherapy in mood disorders: A critical review. Journal of affective disorders.375-379. Doi: 10.1016/j.jad.2020.04.002. [Link]

Costello, C. G., \& Comrey, A. L. (1967). Scales for measuring depression and anxiety. The Journal of Psychology, 66(2), 303-313. Doi: 10.1080/00223980.1967.10544910. [Link]

Demarzo, M. M., Montero-Marin, J., Cuijpers, P., Zabaleta-del-Olmo, E., Mahtani, K. R., Vellinga, A., ... \& García-Campayo, J. (2015). The efficacy of mindfulness-based interventions in primary care: a meta-analytic review. The Annals of Family Medicine, 13(6), 573-582. Doi: 10.1370/afm.1863. [Link]

Ershadi Manesh S. (2021). A controlled comparison of the efficacy of creative problem solving therapy and cognitive behavioural therapy in adolescent' depression. Journal of psychological science, 20(100). 485-501. (Persian). [Link]

Fumero, A., Peñate, W., Oyanadel, C., \& Porter, B. (2020). The effectiveness of mindfulness-based interventions on anxiety disorders. a systematic meta-review. European Journal of Investigation in Health, Psychology and Education, 10(3), 704719.Doi: 10.3390/ejihpe10030052. [Link]

Goldberg, S. B., Tucker, R. P., Greene, P. A., Simpson, T. L., Kearney, D. J., \& Davidson, R. J. (2017). Is mindfulness research methodology improving over time? A systematic review. PloS one, 12(10), e0187298. 10.1371/journal.pone.0187298. [Link]

Graham, J., Haidt, J., Koleva, S., Motyl, M., Iyer, R., Wojcik, S., Ditto, P. (2013). Moral foundations theory: The pragmatic validity of moral pluralism. Advances in Experimental Social Psychology, 47, 55-130.Doi: 10.1016/B978-0-12-407236-7.000024. [Link]

Grecucci, A., Sığırc1, H., Lapomarda, G., Amodeo, L., Messina, I., \& Frederickson, J. (2020). Anxiety regulation: from affective neuroscience to clinical practice. Brain Sciences, 10(11), 846. Doi: 10.3390/brainsci10110846. [Link]

Grecucci, A., Theuninck, A., Frederickson, J., \& Job, R. (2015). Mechanisms of social emotion regulation: From neuroscience to psychotherapy. Emotion regulation: Processes, cognitive effects and social consequences, 57-84. Doi: 10.3389/fpsyg.2017.00985. [Link]

Holder, A., \& Slotkin, P. (2018). Anna Freud, Melanie Klein, and the psychoanalysis of children and adolescents. Routledge.Doi: 10.4324/9780429471827. [Link]

Hong, R. Y., \& Tan, Y. L. (2021). DSM-5 personality traits and cognitive risks for depression, anxiety, and obsessive-compulsive symptoms. Personality and Individual Differences, 169, 110041.Doi: 10.1016/j.paid.2020.110041. [Link]

Hoviatdoost, P., Schweitzer, R. D., Bandarian, S., \& Arthey, S. (2020). Mechanisms of Change in Intensive Short-Term Dynamic Psychotherapy: Systematized Review. American journal of psychotherapy, 73(3), 95-106.Doi: 10.1176/appi.psychotherapy.20190025. [Link]

Jebreel, D. T., Doonan, R. L., \& Cohen, V. (2018). Integrating spirituality within yalom's group therapeutic factors: A theoretical framework for use with adolescents. group, 42(3), 225-244.Doi: 10.13186/group.42.3.0225. [Link]

Kabat-Zinn, J. (2019). Filling up all our Moments. Mindfulness, 10(4), 772-773.Doi: 10.1007/s12671018-1086-x. [Link]

Kohut, H. (2018). The Search for the Self: Selected Writings of Heinz Kohut 1978-1981. Routledge. 
Mamayek, C., Paternoster, R., \& Loughran, T. A. (2017). Self-control as self-regulation: a return to control theory. Deviant behavior, 38(8), 895-916. Doi: 10.1080/01639625.2016.1206730. [Link]

Mansouri J, besharat M. (2019). The mediating role of ego strength between attachment styles and mindfulness. Journal of psychological science, 18(79). 785-796. (Persian). [Link]

McKim, C. A. (2017). The value of mixed methods research: A mixed methods study. Journal of Mixed Methods Research, 11(2), 202-222.Doi: 10.1177/1558689815607096. [Link]

Neborsky, R. J., \& Ten Have-De Labije, J. (2018). Mastering intensive short-term dynamic psychotherapy: a roadmap to the unconscious. Routledge. Doi: 10.4324/9780429477119. [Link]

Prince, E. J., Siegel, D. J., Carroll, C. P., Sher, K. J., \& Bienvenu, O. J. (2020). A longitudinal study of personality traits, anxiety, and depressive disorders in young adults. Anxiety, Stress, \& Coping, 1-9. Doi: 10.1080/10615806.2020.1845431. [Link]

Reangsing, C., Punsuwun, S., \& Schneider, J. K. (2020). Effects of Mindfulness Interventions on Depressive Symptoms in Adolescents: A Meta-Analysis. International Journal of Nursing Studies, 103848.Doi: $\quad$ 10.1016/j.ijnurstu.2020.103848. [Link]

Saeed, S. A., Cunningham, K., \& Bloch, R. M. (2019). Depression and anxiety disorders: benefits of exercise, yoga, and meditation. American family physician, 99(10), 620-627 [Link]

Schore, A. N. (2021). The Interpersonal Neurobiology of Intersubjectivity. Frontiers in Psychology, 12, 1366.Doi: 10.3389/fpsyg.2021.648616. [Link]

Shedler, J. (2015). Integrating clinical and empirical perspectives on personality: The Shedler-Westen Assessment Procedure (SWAP). Personality disorders: Toward theoretical and empirical integration in diagnosis and assessment, 225-252. DOI:10.1037/14549-010. [Link]

Shedler, J., \& Westen, D. (2007). The Shedler-Westen assessment procedure (SWAP): making personality diagnosis clinically meaningful. Journal of personality assessment, 89(1), 41-55. Doi: 10.1080/00223890701357092. [Link]

Shires, A., Sharpe, L., Davies, J. N., \& Newton-John, T. R. (2020). The efficacy of mindfulness-based interventions in acute pain: a systematic review and meta-analysis. Pain, 161(8), 1698-1707.Doi: doi: 10.1097/j.pain.0000000000001877. [Link]
Sword, R. M., Sword, R. K., Brunskill, S. R., \& Zimbardo, P. G. (2014). Time perspective therapy: A new time-based metaphor therapy for PTSD. Journal of Loss and Trauma, 19(3), 197-201.Doi: 10.1080/15325024.2013.763632. [Link]

Town, J. M., Abbass, A., Stride, C., Nunes, A., Bernier, D., \& Berrigan, P. (2020). Efficacy and costeffectiveness of intensive short-term dynamic psychotherapy for treatment resistant depression: 18-Month follow-up of the Halifax depression trial. Journal of Affective Disorders, 273, 194-202.Doi: 10.1016/j.jad.2020.04.035. [Link]

Westen, D., Waller, N. G., Shedler, J., \& Blagov, P. S. (2014). Dimensions of personality and personality pathology: Factor structure of the Shedler-Westen Assessment Procedure-II (SWAP-II). J Pers Disord, 28(2), 281-318.Doi: 10.1521/pedi_2012_26_059. [Link]

Xiang, Y., Dong, X., \& Zhao, J. (2020). Effects of envy on depression: the mediating roles of psychological resilience and social support. Psychiatry Investigation, 17(6), 547-555.Doi: 10.30773/pi.2019.0266. [Link] 